\title{
An Evaluation and Comparison of Vertical Profile Data from the VISSR Atmospheric Sounder (VAS)
}

\author{
GARY J. JEDLOVEC \\ Universities Space Research Association, Atmospheric Sciences Division, Marshall Space Flight Center, Huntsville, AL 35812
}

(Manuscript received 14 November 1984, in final form 30 April 1985)

\section{ABSTRACT}

Statistical procedures are used to compare vertical profiles of temperature and moisture derived from VAS with three different algorithms to those of corresponding rawinsonde measurements for a clear-cold environment. To account for time and space discrepancies between the data, rawinsonde values were adjusted to the satellite sounding times. Both rawinsonde and satellite soundings were objectively analyzed onto a mesoscale grid. These grid point values were compared at $50 \mathrm{mb}$ pressure increments from the surface up to $100 \mathrm{mb}$. The data were analyzed for horizontal and vertical structure, representativeness of derived parameters, and significant departure (improvement) from the a priori (first guess) information.

Results indicate strong temperature and moisture biases in the satellite soundings. Temperature biases of $1-$ $4^{\circ} \mathrm{C}$ and dew-point biases of $2-6^{\circ} \mathrm{C}$ generally occur in layers where strong inversions are present. Magnitudes vary with time as the atmospheric features evolve. The biases change as a function retrieval scheme, suggesting limitations and restrictions on the applications of the various techniques. Standard deviations of temperature range from $1-2^{\circ} \mathrm{C}$ for each retrieval scheme with maxima near 800 and $400 \mathrm{mb}$. Derived parameters (precipitable water and thickness) suffer from similar biases, though to a somewhat lesser extent. Although satellite-derived gradients of basic and derived parameters are generally weaker than those from rawinsondes, they have good horizontal structure where magnitudes of the parameters are relatively strong. Integrated thermal (thickness) and moisture (precipitable water) parameters show mixed results. Although biases are small in the precipitable water values from the regression scheme, horizontal structure is poor.

Analysis of first guess information shows similar biases when compared to the ground truth measurements. This information, however, seems to provide the majority of the vertical structure present in the VAS retrievals.

\section{Introduction}

In the fall of 1980, the first VISSR Atmospheric Sounder (VAS) was launched into geostationary orbit with the GOES-4 satellite. The VAS is a 12-channel radiometer capable of obtaining imagery of the thermal and moisture structure of the atmosphere at short time intervals and small spatial scales over a rather large geographic region. Since 1980 , two other VAS instruments have been launched into geostationary orbit.

Much imagery has been collected and archived from these three instruments over the last several years. However, only a small portion has been used by the meteorological community because it is readily available only via sophisticated computer equipment that can ingest and process the vast quantities of data. For the past several years, the Satellite Field Service Station (SFSS), the National Severe Storms Forecast Center (NSSFC), and the Cooperative Institute for Meteorological Satellite Studies (CIMSS) at the University of Wisconsin have participated in the NOAA Operational VAS Assessment program (NOVA) by utilizing imagery and satellite sounding data in quasi-real time (Anthony and Wade, 1983). Their assessment was not continuous due to many problems related to satellite availability. However, the potential utility of VAS imagery and sounding products was demonstrated. Results also indicated that temperature and height fields from VAS were similar to those from rawinsondes, but dew-point values were unreliable, especially in the lower levels. Derived values of precipitable water and stability were useful to calculate time derivatives (avoiding absolute magnitudes) but are difficult to calculate and monitor over a regional area given the irregular spacing of the VAS retrievals and the movement of the sounding locations with time due to cloudiness.

There have been relatively few studies which examined the accuracy of VAS temperature and moisture information. This is mainly due to the lack of appropriate ground truth data. Menzel et al. (1981), performed an inflight evaluation of radiance data shortly after the first VAS was launched, found discernable time variability in retrieved VAS soundings with rawinsonde/satellite profiles typically within $1-2^{\circ} \mathrm{C}$ of each other and with occasional deviations of $5^{\circ} \mathrm{C}$. Chesters et al. (1982) performed a simulation experiment to evaluate mesoscale features resolvable by VAS using a minimum information linear regression scheme. Results indicated that locally conditioned regression matrices produced temperature errors rang- 
ing from $1-2^{\circ} \mathrm{C}$ at all levels. Mixing ratios were retrieved to within $25 \%$ of the rawinsonde values. Horizontal fields of integrated parameters (thickness and precipitable water) showed good correlation to the ground truth, although a slight reduction in the magnitude of the gradient information was apparent. Lee et al. (1983), investigating the impact of conventional surface data upon VAS regression retrievals, concluded that the absolute temperature and dew-point accuracies using VAS plus surface information were from $1-2^{\circ} \mathrm{C}$ and $1-6^{\circ} \mathrm{C}$, respectively. These values showed a substantial improvement over those without surface data and without regional rawinsonde measurements for training data.

Studies investigating VAS imagery and sounding products in diagnostic analysis (e.g., Smith, 1983; Chesters et al., 1983; and Petersen et al., 1984) and in nowcasting applications (e.g., Anthony and Wade, 1983; Smith and Zhou, 1982) have utilized VAS information at scales of motion (temporal and spatial) at which there is no verifying conventional data. Thus much of the validation for VAS's mesoscale features consisted of actual severe storm events or convective development. When corresponding synoptic scale rawinsonde data were present, discrepancies between the two sources were explained as either acceptable (due to temporal differences) or below the resolution of the ground truth measurements.

In the spring of 1982, NASA's Marshall Space Flight Center, in cooperation with Texas A\&M University, conducted a field experiment to obtain ground truth data at the scales resolvable by VAS (Hill and Turner, 1983). The experiment consisted of making rawinsonde observations over a regional and mesoscale network in the Midwest and Texas at three-hourly intervals during several observational periods which corresponded to VAS measurements. The purpose of this paper is to evaluate the accuracy and representativeness of VAS sounding data from three different retrieval algorithms utilizing the satellite and rawinsonde data from one day of this experiment. Mean and standard deviations of the differences between each data set will be presented along with vertical profiles and horizontal patterns of basic and derived parameters. An analysis of first guess information will be presented to infer the improvements that are made with the retrieval algorithms. Finally, errors in the rawinsonde and the satellite radiances will be evaluated to explain the rawinsonde-satellite discrepancies.

\section{Instrument description and network design}

The VAS is a passive infrared radiometer which senses radiation emitted by the atmosphere and the earth's surface in 12 spectral bands from 3.7 to 15.0 $\mu \mathrm{m}$. Characteristics of these channels are given in Table 1, while Fig. 1 displays the weighting functions for a standard atmosphere (indicating the layer from which radiation is received by VAS). The VAS imagery is collected in scan lines as the GOES satellite spins in a west to east direction. The resolution of each field of view (fov) along a scan line is 7 or $14 \mathrm{~km}$ at nadir depending on whether small or large detectors are used. Only with the large detectors ( $14 \mathrm{~km}$ fov) can the atmosphere be sampled in all 12 channels. When operating in the normal VISSR mode, the GOES spacecraft scans the entire disk of the earth in 18 minutes. Since VAS requires additional spins on the same scan line to improve signal-to-noise ratios in some channels, time requirements force VAS to sample a smaller section, usually an area the size of the continental United States. Within these constraints, VAS can be used to scan this area at intervals of 10-20 minutes, although it is typically done every one to three hours. This frequency and coverage allows for sounding production at resolutions far greater than the conventional observing networks. Additional information about VAS instrument characteristics can be found in Menzel et al. (1981), Smith et al. (1981), and Chesters et al. (1982).

For satellite sounding purposes, the dwell sound (DS) mode of VAS is used whereby multiple samples of upwelling radiances are averaged together to achieve the higher signal-to-noise ratio required for sounding quality radiances. Horizontal averaging of several adjacent fovs may be employed to further improve their quality. Because of this averaging and the spacing of the retrievals, temperature and moisture profiles are described as having a horizontal resolution of 20-75 $\mathrm{km}$. Their vertical resolution is limited by the broadness of the weighting functions (Fig. 1) and is approximately $200 \mathrm{mb}$.

Tó evaluate VAS's fine horizontal resolution, a special experiment was designed to collect ground truth rawinsonde measurements at a similar scale. The 1982 AVE/VAS Ground Truth Field Experiment (Hill and Turner, 1983) collected rawinsonde data at 24 National Weather Service (NWS) sites and 12 special network sites during four different $18 \mathrm{~h}$ observation periods in the spring of 1982 (Fig. 2). During each of these observation periods, three-hourly rawinsonde measurements were made near the times of the VAS dwell sound satellite data. Operating constraints limited the flexibility of the collection periods and, unfortunately, a wide variety of synoptic cases was not sampled. During the most useful case, the regional and mesoscale networks were under clear skies for a number of time periods. This is the case selected for investigation.

\section{Data}

\section{a. Vertical profile information}

Two basic types of data were used in the study, namely, rawinsonde and VAS sounding data for the 6-7 March 1982 AVE/VAS experiment day. The VAS sounding data available for this period consisted of 
TABLE 1. VAS channel characteristics.

\begin{tabular}{|c|c|c|c|c|c|c|c|}
\hline $\begin{array}{l}\text { VAS } \\
\text { CH } \\
=\end{array}$ & $\begin{array}{l}\text { FILT } \\
\text { CENT } \\
\nu\end{array}$ & $\begin{array}{l}\text { FILT } \\
\text { CENT } \\
\mathrm{cm}^{-1}\end{array}$ & $\begin{array}{l}\text { FILT } \\
\text { BAND } \\
\mathrm{cm}^{-1}\end{array}$ & $\begin{array}{l}\text { PURPOSE } \\
\text { FOR } \\
\text { SOUNDING }\end{array}$ & $\begin{array}{l}\text { MAIN } \\
\text { ABS } \\
\text { GAS }\end{array}$ & $\begin{array}{l}\text { OTHER } \\
\text { SIGNIF } \\
\text { EFFECTS }\end{array}$ & $\begin{array}{l}\text { SAMPLE } \\
\text { NOISE } \\
\pm 0 K\end{array}$ \\
\hline 1 & 14.7 & 678 & 10 & TEMP & $\mathrm{CO}_{2}$ & $\mathbf{0}_{3}$ & 5.3 \\
\hline 2 & 14.5 & 691 & 16 & TEMP & $\mathrm{CO}_{2}$ & $\mathbf{0}_{3}$ & 2.2 \\
\hline 3 & 14.3 & 699 & 16 & TEMP & $\mathrm{CO}_{2}$ & $\mathbf{0}_{3}$ & 1.8 \\
\hline $4^{*}$ & 14.0 & 713 & 20 & TEMP & $\mathrm{CO}_{2}$ & $\mathbf{O}_{3}$ & 1.2 \\
\hline $5^{*}$ & 13.3 & 750 & 20 & TEMP & $\mathrm{CO}_{2}$ & $\mathrm{H}_{2} \mathrm{O}$ & 1.0 \\
\hline 6 & 4.5 & 2209 & 45 & TEMP + CLOUD & $\mathrm{CO}_{2}$ & SUN $+\mathrm{N}_{2} \mathrm{O}$ & 1.6 \\
\hline $7^{*}$ & 12.7 & 787 & 20 & MOISTURE & $\mathrm{H}_{2} \mathrm{O}$ & $\mathrm{CO}_{2}$ & 1.0 \\
\hline $8^{*}$ & 11.2 & 892 & 140 & SURFACE & - & $\mathrm{H}_{2} \mathrm{O}+\mathrm{CO}_{2}$ & 0.1 \\
\hline $9^{*}$ & 7.3 & 1370 & 40 & MOISTURE & $\mathrm{H}_{2} \mathrm{O}$ & - & 3.4 \\
\hline $10^{*}$ & 6.8 & 1467 & 150 & MOISTURE & $\mathrm{H}_{2} \mathrm{O}$ & - & 1.6 \\
\hline 11 & 4.4 & 2254 & 40 & TEMP + CLOUD & $\mathrm{CO}_{2}$ & $S U N+N_{2} O$ & 6.7 \\
\hline 12 & 3.9 & 2540 & 140 & SURFACE & - & $\mathrm{SUN}+\mathrm{H}_{2} \mathrm{O}$ & 0.8 \\
\hline
\end{tabular}

*AVAILABLE AT $7 \mathrm{~km}$ (NADIR VIEW) RESOLUTION.

three data sets, each composed of soundings at 1100 , 1435, 1735, 2035, 2335 GMT (beginning satellite scan times). The first set contained vertical profiles of geopotential height, temperature and dew-point temperature at 10 standard levels, and were produced using a scheme similar to that of Smith (1970). The scheme is a physical procedure, where an iterative solution is employed, and LFM model output is used as first guess information. Radiance data from a maximum of 25 (minimum of 4) $14 \mathrm{~km}$ fovs were averaged together before the retrievals were made. Also, some partly cloudy retrievals were acquired using the $N^{*}$ technique (Smith, 1968). These soundings will be referred to as "physical" retrievals. The second data set is similar to the first one except an analytic solution is employed after the initial physical retrievals are obtained in order to provide more vertical structure to the satellite profiles (Smith, 1983). A similar number of clear fields of view were averaged depending on cloud cover, but no attempt was made to retrieve partly cloudy soundings. These soundings will be called "modified physical" retrievals. The third set of VAS soundings was produced using a linear regression scheme as described by Lee et al. (1983). This method uses $25 \mathrm{mb}$ data from the 24 NWS stations (including SEP) at 1200 and 0000
GMT 6 and 7 March 1982 and surface reports to determine statistical relationships between the radiances and the structure of the atmosphere at colocated sites. (Since SEP and other surrounding NWS stations were used to produce gridded fields of rawinsonde parameters (Sec. $4 \mathrm{a}$ ), the regression soundings are not totally independent of the ground truth rawinsonde analysis). These relationships are then applied to the observed radiance measurements to derive temperature and moisture profiles for each of the five time periods. Radiance information from five overlapping fields of view were averaged together before the regression retrievals were made. Thus, considerably less spatial averaging is employed than with the physical retrievals. This data set will be denoted as "regression" soundings. With all three data sets, soundings had horizontal spacings of approximately $50-100 \mathrm{~km}$ over the cloud-free region of Texas, Oklahoma and surrounding states. This spacing (resolution) should not be confused with the area over which radiances were averaged before the production of satellite retrievals as discussed above.

The rawinsonde data used in the evaluation consisted of the basic thermodynamic parameters (geopotential height, temperature, and dew point) at $50 \mathrm{mb}$ increments from the surface up to $100 \mathrm{mb}$ (Sienkiewicz, 


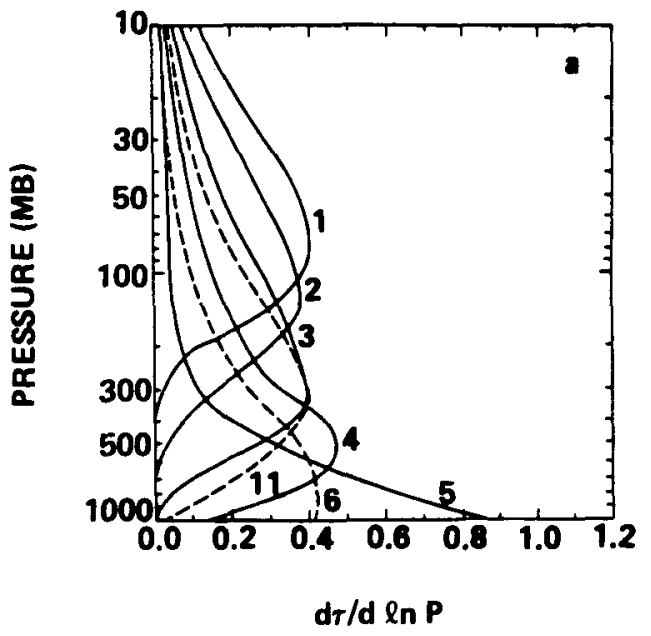

low pressure center was along the Gulf Coast with a stationary front extending southwestward into Mexico. Behind this front, a shallow high pressure area was centered over western Oklahoma. To the north a cold front, extending from a low in Canada, was pushing south through the Upper Plains States.The thermal gradient over the central portion of the region was quite strong, with a packing of isotherms over Texas and over the Central Plains. The western half of the regional network was predominantly cloud free at this time (not shown); however, low clouds persisted in east Texas while convective clouds with thunderstorm activity were present over Louisiana, Arkansas, and Missouri. Several inches of snow were on the ground in portions of Oklahoma and west Texas, but it melted during the afternoon hours.

Aloft, a large amplitude trough at $500 \mathrm{mb}$ was positioned over the regional network in a northeastsouthwest orientation (Fig. 3a).This trough was well defined by the height and wind shear fields (not shown)

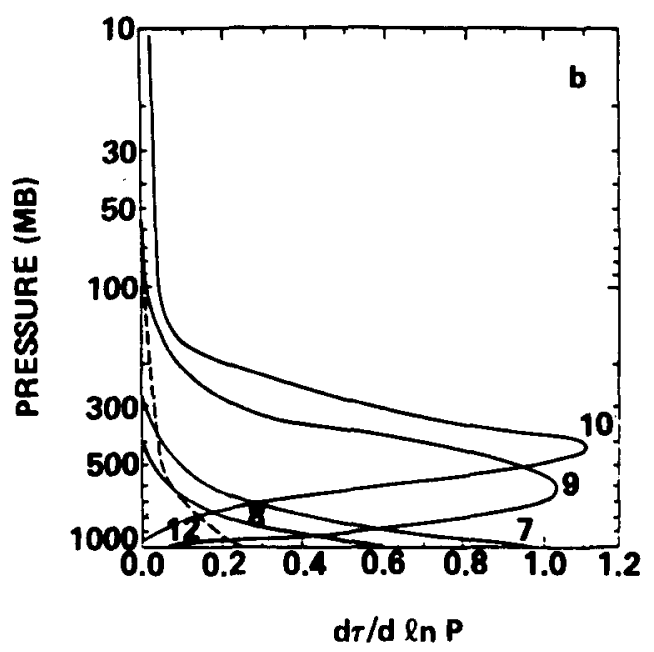

FIG. 1. VAS standard atmosphere weighting functions for the (a) $\mathrm{CO}_{2}$ absorption channels, and (b) water vapor and window channels (from Chesters et al., 1982). Dashed lines indicate shortwave channels.

1982). Rawinsonde locations are shown in Fig. 2. Since their spacing is roughly $125 \mathrm{~km}$, detailed mesoscale resolution of atmospheric features is obtained. The nominal release times of the rawinsonde data were $1200,1500,1800,2100$ GMT on 6 March 1982 and 0000 GMT 7 March 1982.

\section{b. Synoptic and mesoscale conditions}

The 6-7 March 1982 case was selected because a large region of predominately cloud-free skies was over the special network region. Figure 3 presents surface, $500 \mathrm{mb}$, and $300 \mathrm{mb}$ analysis at 1200 GMT 6 March and 0000 GMT 7 March 1982. At 1200 GMT, a surface

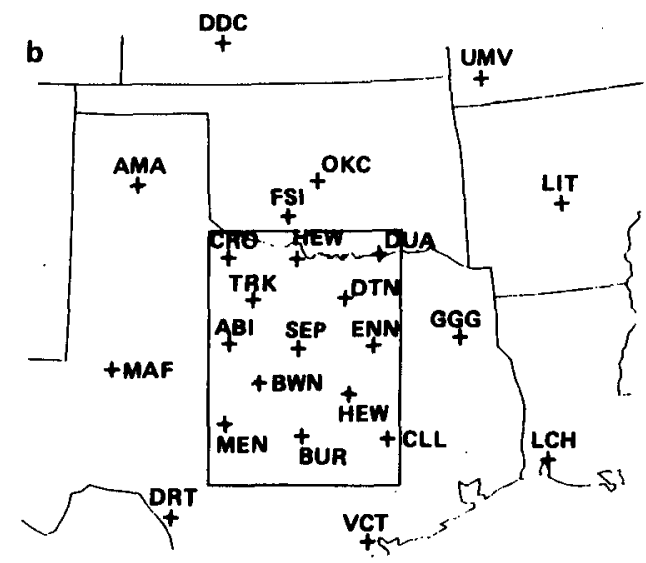

FIG. 2. AVE/VAS rawinsonde sites for the (a) regional and special network, and (b) special mesoscale network sites used in objective analysis and comparisons. The rectangular box locates the $10 \times 13$ grid region. 

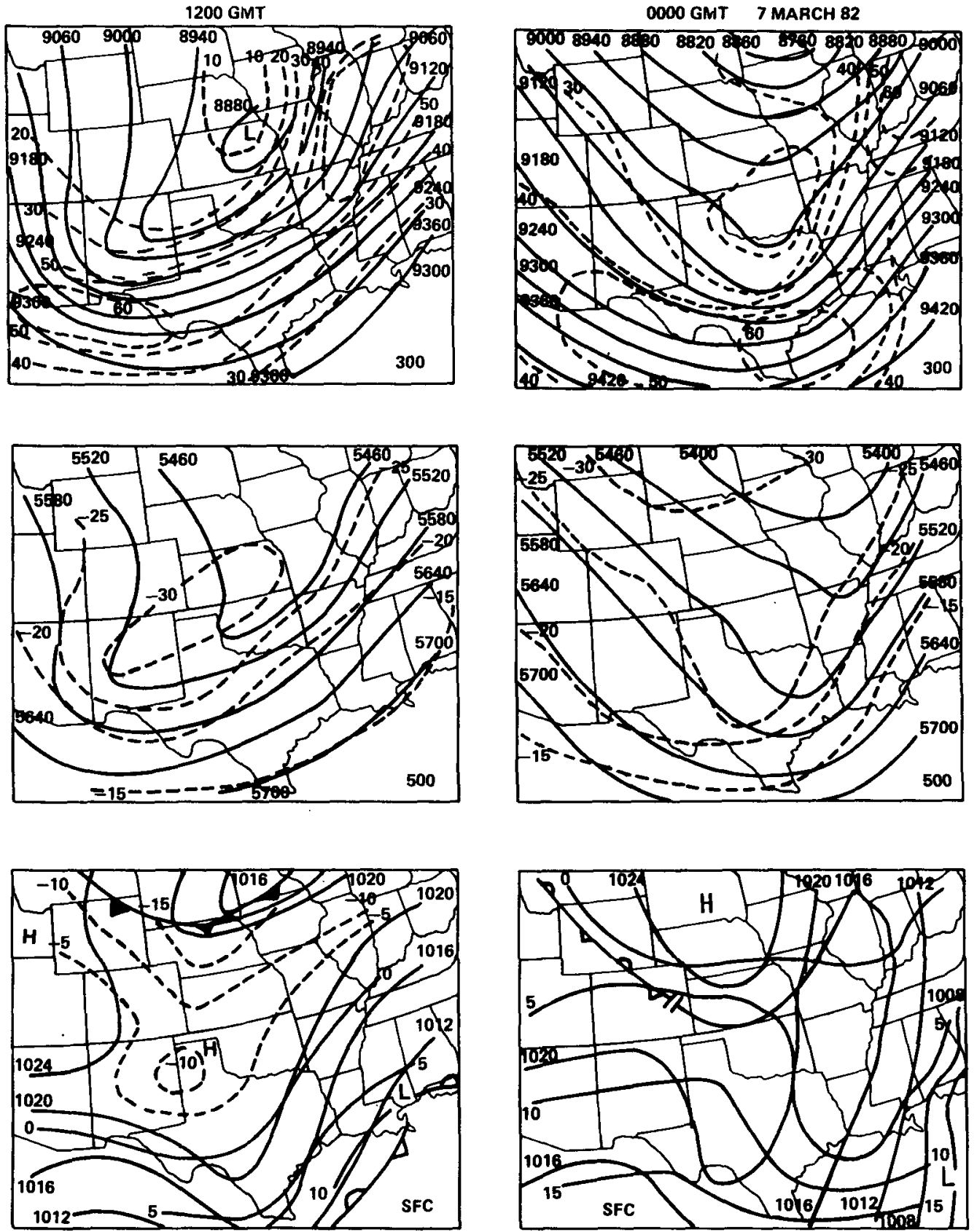

FIG. 3. Surface and upper level synoptic conditions at (a) 1200 GMT 6 March 1982, and (b) 0000 GMT 7 March 1982. Solid contours indicate pressure in millibars at the surface and geopotential heights in meters aloft. Dashed contours indicate temperature in ${ }^{\circ} \mathrm{C}$ for the surface and at $500 \mathrm{mb}$, and isotachs at $300 \mathrm{mb}$ in m s

with a strong thermal gradient through northwest Texas and Oklahoma. A narrow wind maximum was present over the southern portion of the region with maximum winds exceeding $35 \mathrm{~m} \mathrm{~s}^{-1}$ at Stephenville and Tucson. At $300 \mathrm{mb}$, a closed low was present over eastern Nebraska with a well defined trough extending back into New Mexico. A strong jet streak was present over the border of Mexico and the southwest states with maximum winds in excess of $60 \mathrm{~m} \mathrm{~s}^{-1}$.
By 0000 GMT 7 March 1982, the synoptic charts (Fig. 3b) indicate significant movement of the atmospheric features over the last $12 \mathrm{~h}$. The surface low pressure located over the Gulf Coast moved eastward as did the associated showers and thunderstorms. The cold front over the Northern Plains moved south through Kansas and Nebraska bringing even colder and drier air into the region. No precipitation and only scattered clouds were associated with the front in this 
region. Although surface temperatures over the regional network rose considerably during the day, a substantial temperature gradient still existed between the Gulf Coast and the western portion of the experiment region.

At $500 \mathrm{mb}$ (Fig. 3b), the large amplitude wave shifted slightly eastward but its southern extension rotated rapidly through the mesoscale network by 0000 GMT. The strong thermal gradient present at 1200 GMT (Fig. 3a) moved through central Texas and was positioned over southern and eastern Texas just beyond the mesoscale network (see Fig. 2). The progression of this cold feature through the mesoscale rawinsonde network was well captured by the three-hourly data and is discussed below. The $300 \mathrm{mb}$ diagram shows an equally rapid shift of the trough line through west Texas. A well defined jet streak is present at the base of the trough with winds still exceeding $60 \mathrm{~m} \mathrm{~s}^{-1}$.

The three-hourly data collected from the special network over Texas (Fig. 2) captured many mesoscale features. Two of the most prominent are low-level drying behind the front and the propagation of a small pocket of cold midtropospheric air over the region. Figure 4 presents $850 \mathrm{mb}$ analyses of temperature and dew-point depression for five times from 1100 through
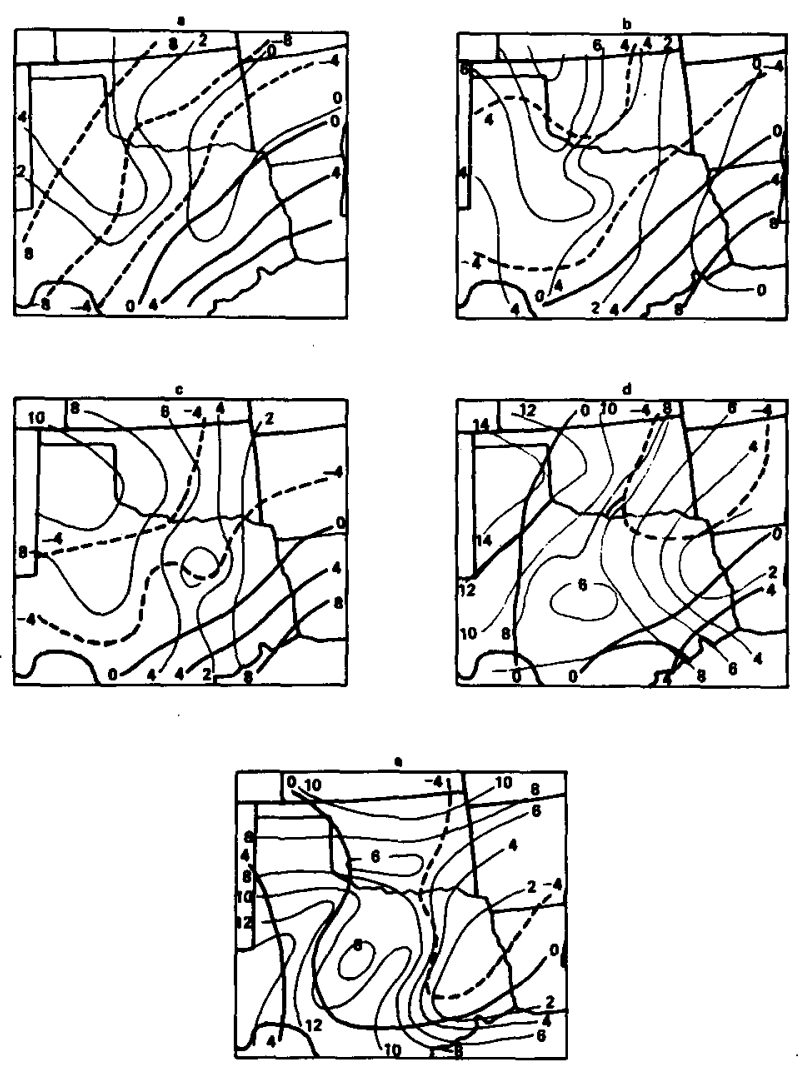

FiG. 4. Mesoscale analysis of temperature (bold lines) and dewpoint depression (thin lines) for $850 \mathrm{mb}$ at (a) $1100 \mathrm{GMT}$, (b) 1445 GMT, (c) 1745 GMT, (d) 2045 GMT, and (e) 2345 GMT 6 March 1982. Units are in ${ }^{\circ} \mathrm{C}$. Dashed temperature lines indicate negative values.
2345 GMT. One should recall the frontal positions described above (Fig. 3a, b) and the cloud cover at 1800 GMT presented in Fig. 5. The $850 \mathrm{mb}$ temperature patterns (heavy lines) indicate a structure somewhat similar to the surface fields with a northwest-southeast temperature gradient behind the frontal zone. Coldest temperatures are over west Texas and Oklahoma. This pattern weakens during the day as solar heating warms the lowest layer in the cloud-free regions. This is apparent between 1745 and 2045 GMT when the entire mesoscale network becomes cloud free. By 2345 GMT the temperature gradient has almost reversed with warm air over west Texas and a moderate gradient extending eastward through the special network. Dewpoint depressions (thin lines) indicate a saturated or nearly saturated lowest layer in the eastern portions of the mesoscale region. This moist feature moves eastward with the cloud cover (Fig. 5) as drier air with dew-point depression values greater than $10^{\circ} \mathrm{C}$ enters the mesoscale region by 2045 GMT. Very fine-scale structure is observed at this level.

The $500 \mathrm{mb}$ analyses over the mesoscale region are presented in Fig. 6 . The mesoscale data more accurately define the position and movement of the trough and temperature field through the Texas and Oklahoma region than do the conventional synoptic-scale data (Fig. 3). In addition, the data pinpoint the temperature minimum located immediately behind the trough line as it progresses through the network. The ability of VAS to detect this feature will be described later.

\section{Methodology}

\section{a. Time and space adjustments}

Rawinsonde and satellite soundings are rarely colocated in space or taken at the same times, thus making comparisons between them difficult to interpret. To overcome this problem, special procedures were used to make the rawinsonde and satellite data more consistent. First, the ground truth rawinsonde data were adjusted to a common release time (10 min after the beginning satellite scan time) using a scheme described by Fuelberg and Jedlovec (1982). The new rawinsonde times are 1100, 1445, 1745, 2045, 2345 GMT 6 March 1982. This procedure provided rawinsonde and satellite data which were valid at the same times at all levels of the atmosphere. Second, the satellite profiles were interpolated to constant pressure levels of $50 \mathrm{mb}$ increments from the standard pressure levels that were supplied. In the case of the regression soundings, geopotential heights were calculated from the temperature and moisture profiles using the hypsometric equation. Finally, the rawinsonde and satellite data were objectively analyzed to a $10 \times 13$ uniform grid over central Texas, with the balloon position (radiosonde) being calculated at every level. This procedure helped eliminate any spatial discrepancies between the data sets 


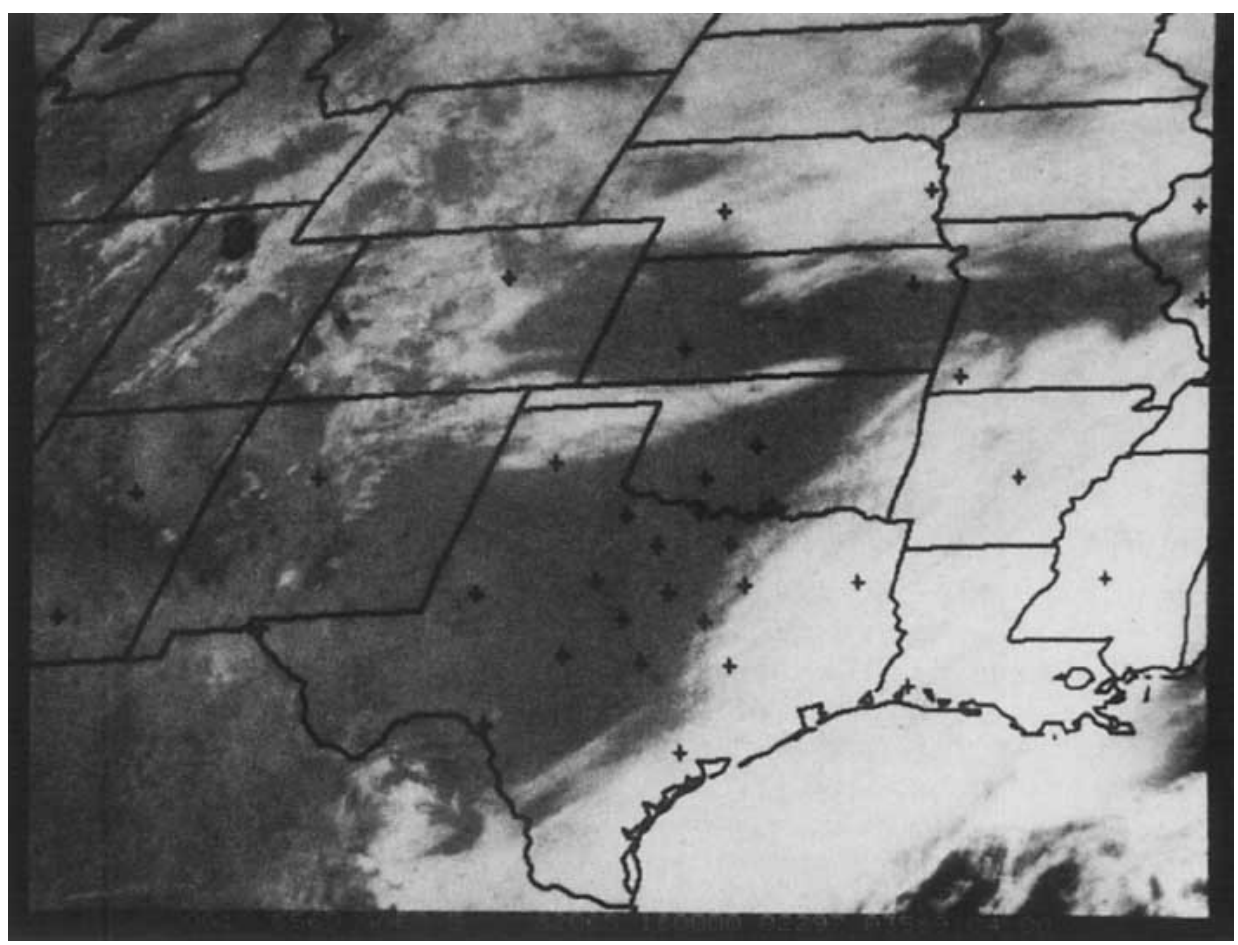

FIG. 5. Visible image from the GOES East satellite at 1800 GMT 6 March 1982. Rawinsonde sites are superposed on the image.
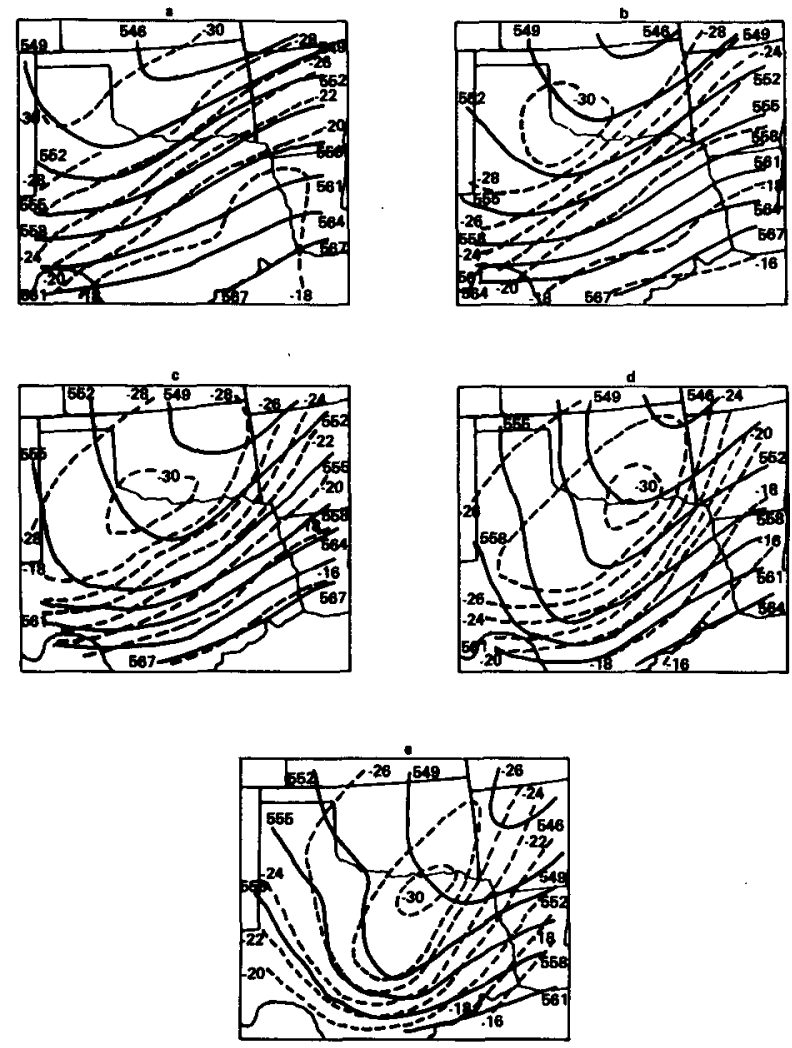

since the same grid was used for all data sets (Fig. 2b). In addition, the same objective analysis parameters were utilized with each data set so that the potential for detail in the gridded fields was similar at each level and time, and for each data set. In the cases where part of the analysis region was void of satellite soundings due to clouds (mainly 1100 and 1445 , but to a lesser extent at 1745) grid point values were not determined to avoid misrepresenting atmospheric features.

The procedures followed in this evaluation and described above have provided three sets of satellite data and a set of ground truth rawinsonde data on constant pressure surfaces at $50 \mathrm{mb}$ increments from the surface to $100 \mathrm{mb}$. In addition to the basic parameters (height, temperature, and dew point), grid point values of precipitable water, thickness over three layers of the atmosphere, gradient and time change information were calculated and similarly evaluated.

\section{b. Statistical calculations}

Utilizing the identically gridded rawinsonde and satellite data, mean differences and standard deviations

FIG. 6. Mesoscale analysis of geopotential height (solid) and temperature (dashed) at $500 \mathrm{mb}$ for (a) $1100 \mathrm{GMT}$, (b) $1445 \mathrm{GMT}$, (c) 1745 GMT, (d) 2045 GMT and (e) 2345 GMT 6 March 1982. Units are decameters and ${ }^{\circ} \mathrm{C}$ for height and temperature, respectively. 
of differences were computed between the rawinsonde and satellite grids. Although each point is not an independent value, enough observations (greater than 15 for rawinsonde and greater than 30 for the satellite soundings) were allowed to influence the gridded field such that statistical significance was maintained. The statistical parameters were calculated only over the regions of the grid where valid observations existed. Additionally, horizontal fields of basic and derived parameters and vertical profiles of grid mean values were analyzed.

\section{Results}

\section{a. Statistical comparison-all times combined}

Tables 2-6 present mean differences and standard deviations of the differences between the rawinsonde and each satellite data set for all five observation times combined. The total number of grid points used varies from one satellite data set to another due to the differing numbers and locations of the soundings with respect to the cloud fields. These variations should not produce significant differences when results from one retrieval algorithm are compared to another. Although the composite results mask the diurnal variability, they provide general information about the quality of the data that can be used for comparison with those from other remote sensing instruments. The diurnal variability will be addressed in a following section.

Mean temperature differences (Table 2) for the composite period indicate overall temperature bias in each VAS data set. In this context and those which follow (except in section $5 e$ where the biases in the LFM data are discussed), the term "bias" refers to the discrepancy between the rawinsonde and satellite derived values due to the partiality of the retrieval techniques and weighting functions to provide a prescribed value at a single level or in a layer which is different from the known value. Since the satellite values are subtracted from those of the ground truth rawinsonde (rao - sat), a negative (positive) number indicates a warm (cold) bias. The bias pattern is similar for each retrieval method with a warm bias in the lowest 150 $\mathrm{mb}$ capped by a cold bias from $800 \mathrm{mb}$ to approximately $650 \mathrm{mb}$. The magnitude of the warm bias is 2$3^{\circ} \mathrm{C}$ for each scheme. The cold bias in the low levels is greatest in the modified physical retrievals with values as high as $2.6^{\circ} \mathrm{C}$ at $750 \mathrm{mb}$. Bias values for this layer remain below $1.0^{\circ} \mathrm{C}$ for the physical and regression schemes. In the middle and upper troposphere (600-

TABLE 2. Mean and standard deviation of the differences between the rawinsonde and satellite grid point temperature values for a composite of five time periods on 6 March 1982. The values below each data set name indicate the number of grid points used in the calculations. Units are in ${ }^{\circ} \mathrm{C}$.

\begin{tabular}{|c|c|c|c|c|c|c|}
\hline \multirow{2}{*}{\multicolumn{3}{|c|}{$\begin{array}{c}\text { TEMPERATURE } \\
\text { PHYSICAL } \\
\text { 638 } \\
\text { MEAN STD. DEV. }\end{array}$}} & \multirow{2}{*}{\multicolumn{2}{|c|}{$\begin{array}{c}\text { ALL-TINES (1-5) } \\
\text { MODIFIED PHYSICAL } \\
587 \\
\text { MEAN STO. DEV. }\end{array}$}} & \multirow{2}{*}{\multicolumn{2}{|c|}{$\begin{array}{l}\text { REGRESSION } \\
510 \\
\text { MEAN STD. DEV. }\end{array}$}} \\
\hline & & & & & & \\
\hline 100 & -2.4 & 1.1 & -0.8 & 0.9 & 0.6 & 0.7 \\
\hline 150 & -0.2 & 1.0 & 1.4 & 0.8 & -0.2 & 0.7 \\
\hline 200 & -0.1 & 1.3 & 1.3 & 1.0 & 1.6 & 0.9 \\
\hline 250 & -1.3 & 1.4 & -0.4 & 1.3 & 0.4 & 2.0 \\
\hline 300 & -1.7 & 1.6 & -1.2 & 1.4 & 0.0 & 1.8 \\
\hline 350 & -2.2 & 0.9 & -1.6 & 0.9 & -1.6 & 1.1 \\
\hline 400 & -1.7 & 1.4 & -1.1 & 1.5 & -1.6 & 1.4 \\
\hline 450 & -2.0 & 1.7 & -1.7 & 2.0 & -2.4 & 1.9 \\
\hline 500 & -1.7 & 1.6 & -1.4 & 1.8 & -2.4 & 1.9 \\
\hline 550 & -1.2 & 1.3 & -0.5 & 1.3 & -1.7 & 1.5 \\
\hline 600 & -0.6 & 1.1 & 0.5 & 1.2 & -0.6 & 1.2 \\
\hline 650 & 0.3 & 1.0 & 1.8 & 1.2 & 0.2 & 1.1 \\
\hline 700 & 0.4 & 1.1 & 2.3 & 1.4 & 0.3 & 0.9 \\
\hline 750 & 0.8 & 1.1 & 2.6 & 1.3 & 0.9 & 1.0 \\
\hline 800 & 0.5 & 1.0 & 1.7 & 1.3 & 0.3 & 1.3 \\
\hline 850 & -2.5 & 1.5 & -0.8 & 1.4 & -1.5 & 1.3 \\
\hline 900 & -3.8 & 1.4 & -2.9 & 1.3 & -3.2 & 1.3 \\
\hline SFC & 0.7 & 1.4 & 0.8 & 1.4 & 0.4 & 1.4 \\
\hline
\end{tabular}


$300 \mathrm{mb}$ ), a fairly strong warm bias exists in all retrieval schemes with values ranging from $1-2^{\circ} \mathrm{C}$. Maximum biases occur around $400 \mathrm{mb}$. Above $300 \mathrm{mb}$, the physical retrievals maintain a warm bias while the modified physical and regression schemes vary but generally indicate a cold bias. Vertical variations in bias patterns seem to reflect the inability of the VAS instrument and retrieval schemes to resolve the detailed vertical structure provided by the rawinsonde data (discussed later). Despite these temperature biases, standard deviations of the difference fields show similar patterns for all three data sets. Values range from $1-2^{\circ} \mathrm{C}$ with maximum deviations occuring around $450-500 \mathrm{mb}$ and $250 \mathrm{mb}$. A secondary maximum exists in the very lowest layer where the warm/cold bias couplet exists.

Corresponding data for dew point are presented in Table 3. Moisture biases, indicated by the mean differences, are quite large for the two physical retrieval schemes but are relatively small for the regression scheme. Both of the physical schemes are too moist (warm) in almost the entire lower and middle troposphere, with maximum mean dew-point differences (rao - sat $<0$ ) in excess of $-6^{\circ} \mathrm{C}$ at $750 \mathrm{mb}$. The modified physical scheme indicates a dry (cold) bias of several degrees above $550 \mathrm{mb}$ but the physical scheme does not produce dry conditions until $400 \mathrm{mb}$. Standard deviations of the dew-point temperature differences for these two schemes range from $1-2^{\circ} \mathrm{C}$ in the lowest layers up to almost $6^{\circ} \mathrm{C}$ in the middle troposphere. The regression retrievals indicate only a small dry (cold) bias at the lowest three levels and a slight moist (warm) bias above this. Bias values are less than $2{ }^{\circ} \mathrm{C}$ at all levels. Despite these small biases, standard deviations of the dewpoint differences are larger than expected and range from $2-5^{\circ} \mathrm{C}$ with maximum deviations occuring around 650 and $400 \mathrm{mb}$. Although these values are not as high as for the physical schemes, they indicate a considerable amount of discrepancy from the ground truth data. This will be considered further in a later section.

Geopotential height values for the satellite profiles are derived from the thermal and moisture fields. Any bias patterns reflected in the satellite temperatures should be evident in the height statistics as well. Vertical variations in warm/cold temperature biases may cancel to produce a small height discrepancy, whereas constant temperature biases will accumulate (i.e., increase the thickness) to produce increasing height biases with decreasing pressure. Both of these situations occur in the geopotential height data from the VAS satellite soundings on 6 March 1982 . Table 4 presents means and standard deviations of the differences for the geopotential heights for all five times grouped together. As expected, the influence of the temperature biases can be seen in the mean height differences. For the physical retrievals, the low level warm/cold bias pair

TABLE 3. As in Table 2 except for dew-point temperature.

DEWPOINT TEMPERATURE ALL-TIMES (1-5) RAO- SAT

\begin{tabular}{|c|c|c|c|c|c|c|}
\hline & PHY & $\begin{array}{l}\text { YSICAL } \\
638\end{array}$ & MODIFIE & $\begin{array}{l}\text { ED PHYSICAL } \\
587\end{array}$ & REG & $\begin{array}{l}\text { RESSION } \\
510\end{array}$ \\
\hline & MEAN & STO. DEV. & MEAN & STD. DEV. & MEAN & STD. DEV. \\
\hline 100 & - & - & - & - & - & - \\
\hline 150 & - & - & - & - & - & - \\
\hline 200 & - & - & - & - & - & - \\
\hline 250 & - & - & - & - & - & - \\
\hline 300 & - & - & - & - & - & - \\
\hline 350 & - & - & - & - & - & - \\
\hline 400 & 4.0 & 3.6 & 2.7 & 4.5 & 1.2 & 4.8 \\
\hline 450 & -0.8 & 4.8 & 1.3 & 5.1 & -1.0 & 3.1 \\
\hline 500 & -2.4 & 4.6 & 2.8 & 5.4 & -0.8 & 2.4 \\
\hline 550 & -4.4 & 5.0 & -0.6 & 4.6 & -1.4 & 3.3 \\
\hline 600 & -3.8 & 5.4 & -1.7 & 5.2 & -0.4 & 4.3 \\
\hline 650 & -4.8 & 5.9 & -3.8 & 5.7 & -1.1 & 4.4 \\
\hline 700 & -5.9 & 5.5 & -5.9 & 5.5 & -1.5 & 3.3 \\
\hline 750 & -6.5 & 4.8 & -6.1 & 4.3 & -1.6 & 2.4 \\
\hline 800 & -4.0 & 4.1 & -3.4 & 3.5 & 0.7 & 1.7 \\
\hline 850 & -1.8 & 2.3 & -1.4 & 2.2 & 1.4 & 1.5 \\
\hline 900 & -1.0 & 1.4 & -0.7 & 1.4 & 1.5 & 1.4 \\
\hline SFC & 1.5 & 2.4 & 1.4 & 2.5 & 1.0 & 2.3 \\
\hline
\end{tabular}


TABLE 4. As in Table 2 except for geopotential height. Units are in meters.

\section{GEOPOTENTIAL HEIGHT ALL-TIMES (1-5) RAO-SAT}

\begin{tabular}{|c|c|c|}
\hline & \multicolumn{2}{|c|}{$\begin{array}{c}\text { PHYSICAL } \\
638\end{array}$} \\
\hline & MEAN & STD. DEV. \\
\hline 100 & -61.0 & 27.0 \\
\hline 150 & -44.0 & 23.0 \\
\hline 200 & -46.0 & 22.0 \\
\hline 250 & -42.0 & 21.0 \\
\hline 300 & -31.0 & 21.0 \\
\hline 350 & -19.0 & 20.0 \\
\hline 400 & -13.0 & 18.0 \\
\hline 450 & -6.9 & 15.0 \\
\hline 500 & -4.8 & 12.0 \\
\hline 550 & 2.4 & 12.0 \\
\hline 600 & 4.6 & 11.0 \\
\hline 650 & 4.9 & 9.2 \\
\hline 700 & 4.2 & 7.9 \\
\hline 750 & 3.0 & 7.2 \\
\hline 800 & 2.1 & 7.2 \\
\hline 850 & 4.3 & 6.8 \\
\hline 900 & 6.5 & 5.7 \\
\hline SFC & - & - \\
\hline
\end{tabular}

MODIFIED PHYSICAL

587

MEAN STD. DEV.

\begin{tabular}{rr}
\hline 5.6 & 22.0 \\
3.5 & 23.0 \\
-11.5 & 20.0 \\
-14.0 & 20.0 \\
-7.0 & 23.0 \\
1.8 & 23.0 \\
6.3 & 20.0 \\
11.0 & 17.0 \\
17.0 & 14.0 \\
20.0 & 13.0 \\
20.0 & 11.0 \\
17.0 & 9.3 \\
13.0 & 7.5 \\
8.0 & 6.6 \\
3.9 & 6.6 \\
3.2 & 6.6 \\
8.6 & 5.8 \\
- & - \\
\hline
\end{tabular}

\section{REGRESSION \\ 510}

MEAN STD. DEV.

\begin{tabular}{rr}
\hline-25.0 & 25.0 \\
-27.0 & 27.0 \\
-37.0 & 27.0 \\
-44.0 & 28.0 \\
-44.0 & 31.0 \\
-37.0 & 31.0 \\
-32.0 & 28.0 \\
-25.0 & 23.0 \\
-17.0 & 18.0 \\
-11.0 & 15.0 \\
-8.4 & 12.0 \\
-7.8 & 10.0 \\
-8.4 & 8.6 \\
-9.8 & 7.8 \\
-11.0 & 7.1 \\
-10.0 & 6.4 \\
-5.7 & 6.1 \\
- & - \\
\hline
\end{tabular}

produce compensating thickness values below $550 \mathrm{mb}$ and result in very little height bias at the middle levels. Above this level, a nearly constant warm bias (Table 2) creates increasingly erroneous height values which are $60 \mathrm{~m}$ too high. The modified physical retrievals, which were extremely cold biased in the $800-600 \mathrm{mb}$ layer, produced height values that are $20 \mathrm{~m}$ too low in the mean. These low height biases are not cancelled until $300 \mathrm{mb}$ where the middle and upper level warm biases greatly increase the thickness values. Mean height differences for the regression retrievals are too high $($ rao - sat $<0)$ for the entire column. This occurs despite some cold biases near $750 \mathrm{mb}$ and $250 \mathrm{mb}$ because the warm biases are too great. Maximum differences occurring in the 300 to $250 \mathrm{mb}$ layer are less than those for the physical scheme but are greater than those for the modified physical scheme. The standard deviations of the height differences are almost identical for the two physical schemes. Maximum values near $20 \mathrm{~m}$ occur in the upper levels. Standard deviations for the regression scheme indicate a similar profile but reach $31 \mathrm{~m}$ at 350 and $300 \mathrm{mb}$.

Parameters which represent layer values can be used to counteract level biases due to poor vertical resolution in the VAS thermal channels. Tables 5 and 6 present statistical results for thickness calculated over four layers of the atmosphere, and for precipitable water from the surface through $350 \mathrm{mb}$. Results indicate many of the biases previously discussed (Tables 2-4). Mean thickness differences for the four layers (Table 5) vary with each retrieval scheme but correspond to the individual temperature biases. Each retrieval set indicates that thickness is too great in the $500-250 \mathrm{mb}$ layer (warm temperature bias) with the physical retrieval scheme being the most biased at $-41.0 \mathrm{~m}$. With the exception of the physical retrievals in the uppermost layer, the standard deviations of thickness differences are almost identical between retrieval schemes. Maximum thickness deviations of around $20 \mathrm{~m}$ occur in the 250-100 mb layer.

The physical and modified physical schemes indicate excessive moisture in the precipitable water values, while the regression scheme is slightly dry biased (Table 6). This could have been inferred from the dew-point bias patterns shown in Table 3. Standard deviations are also high for the physical schemes being around $1.5 \mathrm{~mm}$. The standard deviation of the precipitable water difference for the regression soundings is $0.9 \mathrm{~mm}$ for the entire column.

\section{b. Statistical comparison for individual times}

The statistical results presented in Tables 2-6 provide an overall estimate of the biases and errors in each of 
TABLE 5. As in Table 2 except for thickness calculated over four layers of the atmosphere. Units are in meters.

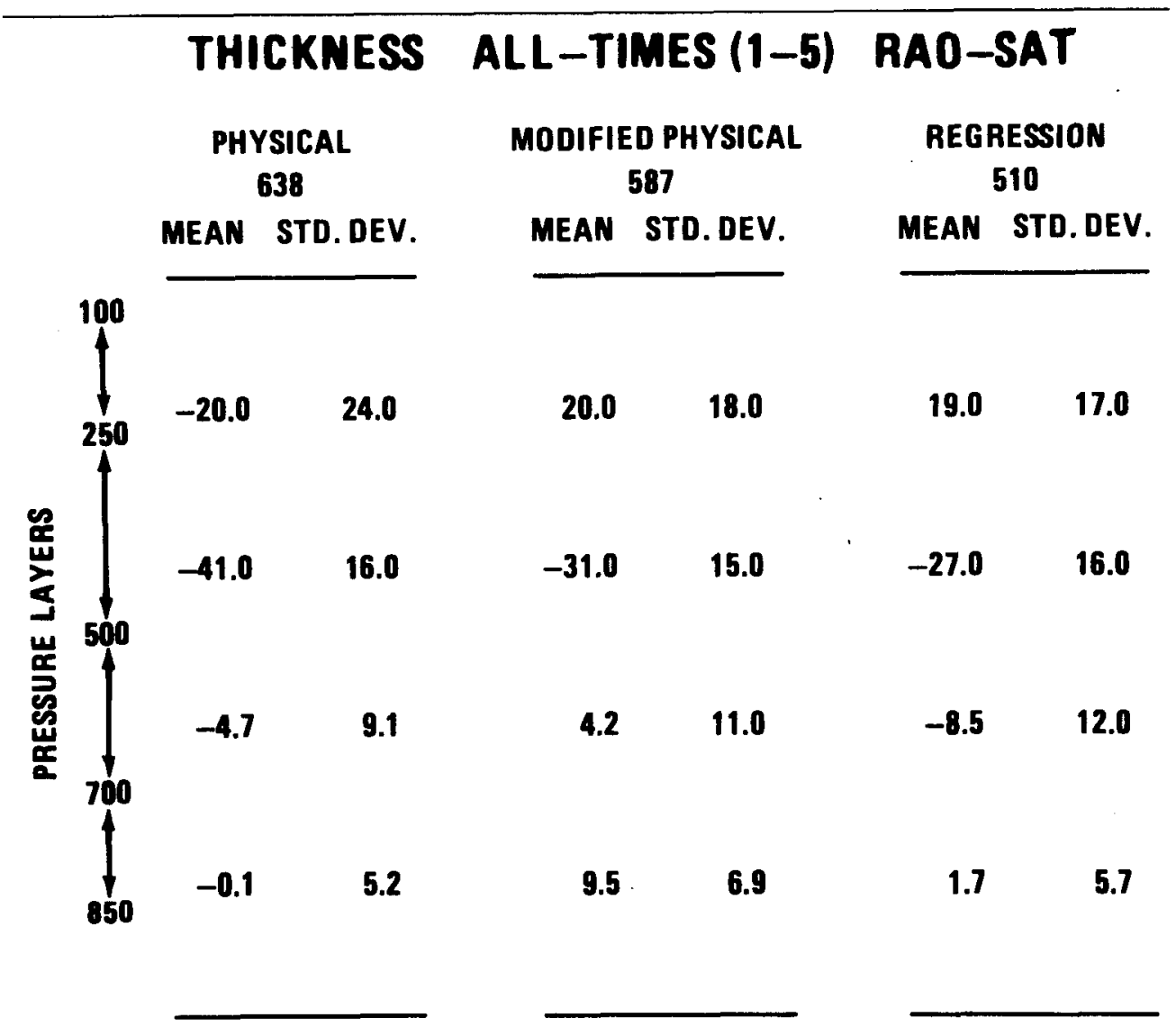

the VAS retrieval data sets. The discussion below addresses these issues at individual observation times.

Figure 7 presents the mean temperature difference for each satellite data set as a function of time and pressure. The number of grid points used in the evaluation at each time (occasionally less than the maximum of 130 due to clouds over the grid area) is given below each profile. Several important features were not apparent in the composite results (Table 2). First, the low-level warm/cold bias couplet is present at most times and has the largest values at the first two observation times. This feature is present in the regression soundings at all times but changes to a warm bias in the physical and modified physical retrievals for the last two time periods. Figure 8 presents thermodynamic diagrams of grid mean profiles of rawinsonde data. It is readily apparent that the low-level temperature bias couplet is due to the strong frontal inversion in the

TABLE 6. As in Table 2 except for precipitable water in the column from the surface to $350 \mathrm{mb}$. Units are in millimeters.

\section{PRECIPITABLE WATER ALL-TIMES (1-5) RAO - SAT}

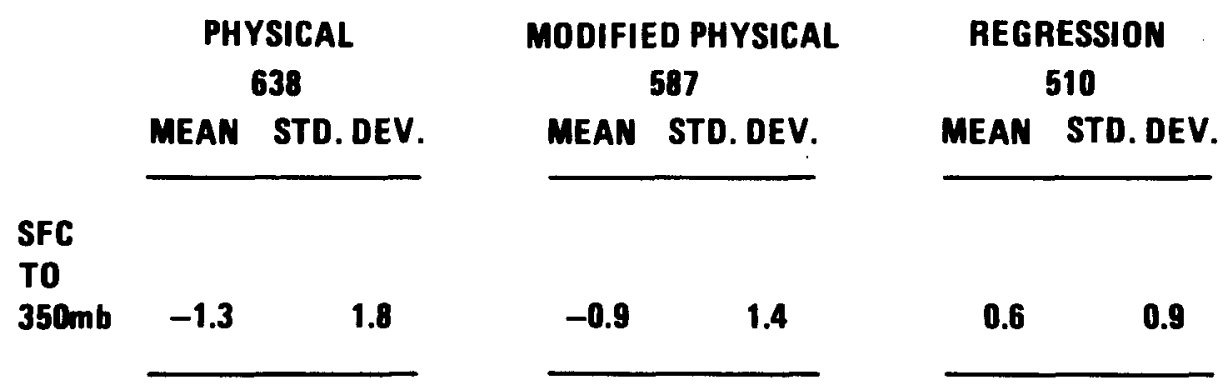


MEAN DIFFERENCE (RAO-SAT)

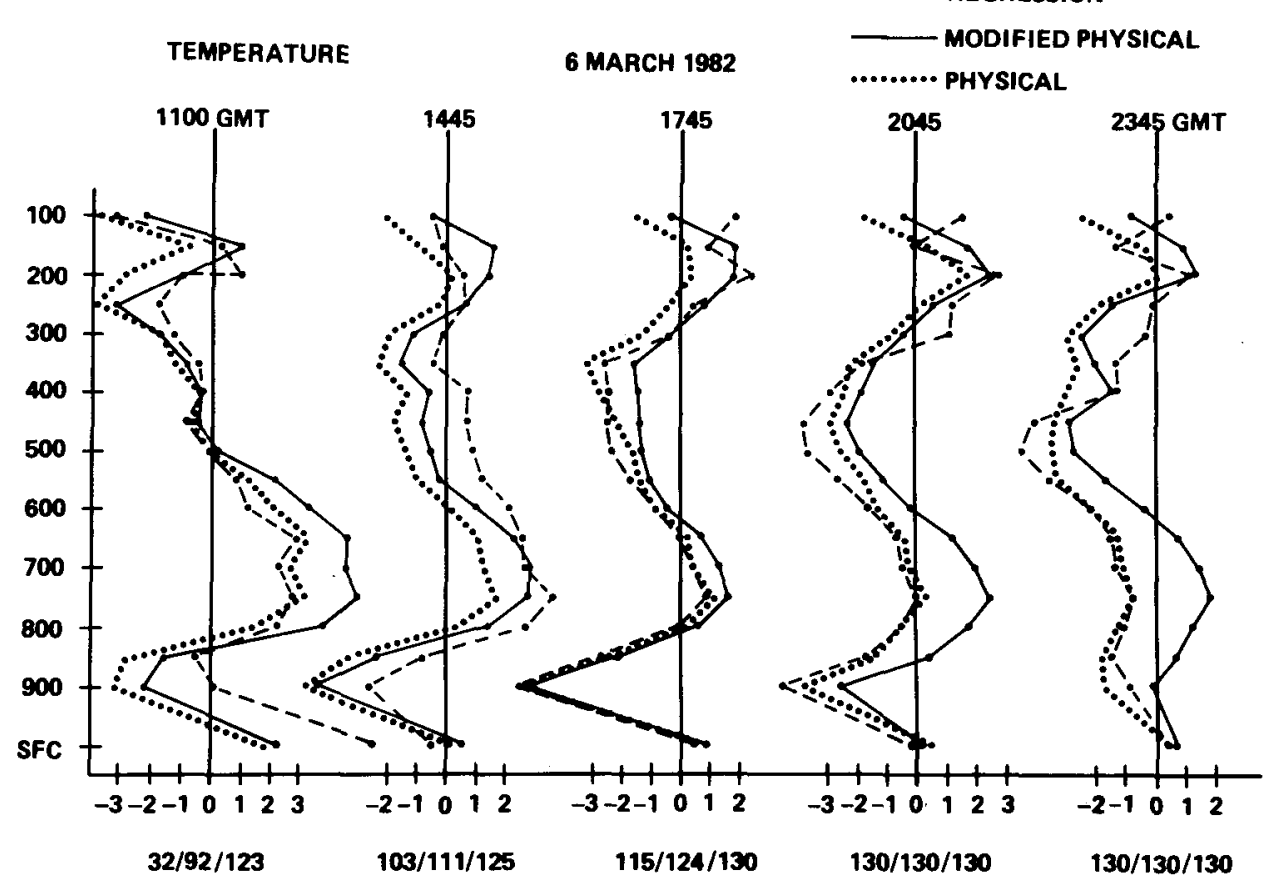

FIG. 7. Mean temperature difference between rawinsonde and satellite grid point values as a function of pressure and time. Dashed lines correspond to regression retrievals, solid lines to the modified physical retrievals, and dotted lines to the physical retrievals. The values below each set of profiles correspond to the number of grid points utilized at each time. All units are in ${ }^{\circ} \mathrm{C}$.
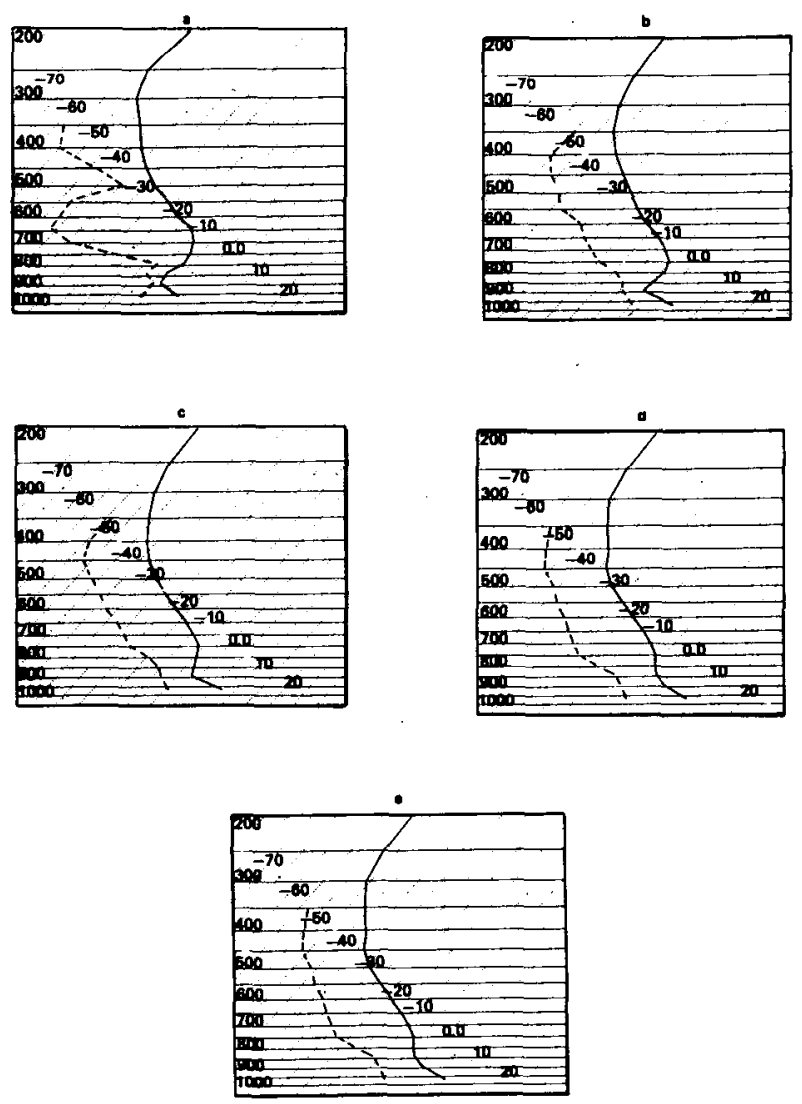

900 to $700 \mathrm{mb}$ layer. This inversion weakens with time as high pressure moves over the region (Fig. $3 \mathrm{a}, \mathrm{d}$ ) and as insolation warms the boundary layer. The smaller biases in the VAS low-level temperatures at 2045 and 2345 GMT seem related to the weakening of this inversion. Another feature in the mean temperature profiles provides an explanation for temperature bias patterns in the middle and upper layers. The tropopause inversion present at $1100 \mathrm{GMT}$ (Fig. 8a) around 250 $\mathrm{mb}$ lowers onto the frontal boundary with time to create a fairly strong inversion by 1745 GMT (Fig. 8c). This feature, combined with the poor vertical resolution of the middle and upper tropospheric VAS channels (Fig. 1) and the low signal-to-noise ratios in these channels, seems to prevent an accurate determination of the inversion level. This results in the middle level temperature biases observed in all three retrieval schemes at 1745, 2045, and 2345 GMT. These warm biases are maximized at 2045 GMT with values between $-2^{\circ}$ and $-4^{\circ} \mathrm{C}$ from 600 through $350 \mathrm{mb}$. The regression scheme is most biased in this region with a maximum value of $-3.9^{\circ} \mathrm{C}$ at $450 \mathrm{mb}$. This warm bias is capped by a cold bias (rao - sat $>0$ ) above $300 \mathrm{mb}$ at 1745 and 2045 GMT in a similar fashion to the lowlevel bias couplet.

FiG. 8. Grid mean temperature and dew-point skew- $t$ profiles for the rawinsonde data at (a) 1100 GMT, (b) 1445 GMT, (c) 1745 GMT, (d) 2045 GMT, and (e) 2345 GMT 6 March 1982. 
Figure 9 presents mean dew-point temperature differences over the mesoscale grid region. The difference profiles exhibit many of the biases noted in the composite results (Table 3 ) but also indicate some diurnal variation. The physical and modified physical schemes have a moist (warm) bias (rao - sat $<0$ ) through most of the column between 1100 and 1745 GMT. Maximum difference values for these schemes exceed $-8^{\circ} \mathrm{C}$ around $700 \mathrm{mb}$. The physical schemes become slightly less biased in the lowest layers at 2045 and 2345 GMT but become dry (cold) biased above $600 \mathrm{mb}$ at these times. Maximum dry biases exceed $5^{\circ} \mathrm{C}$ in the 450 to $350 \mathrm{mb}$ layer. Except for the very large moist (warm) bias at 1100 GMT, the regression retrievals exhibit only minor dew-point temperature biases. The large bias in the 750 to $550 \mathrm{mb}$ layer at the first time may be due to the relatively few data points used in the calculation due to cloud cover; however, similar biases exist for the two physical schemes with a larger number of grid points. Biases for the regression retrievals are generally less than $3^{\circ} \mathrm{C}$ but tend to be somewhat larger in the upper levels. Recalling the mean dew-point profile from the rawinsonde data (Fig. 8), the greatest vertical variation of moisture exists at the first time when moist air exists below $800 \mathrm{mb}$ and in a thin layer from 550 to $400 \mathrm{mb}$. These levels correspond to the large biases noted previously. At the later times, vertical variations in the mean dew-point profiles become smaller and the satellite biases decrease as well.

Time variations of geopotential height biases are presented in Fig. 10. They correspond directly to the temperature biases indicated in Fig. 7. The warm tem- perature biases which are prevalent in the middle troposphere after 1745 GMT produce relatively large height biases above $500 \mathrm{mb}$. This was only vaguely apparent in the composite results in Table 4. Biases for the regression scheme exceed $-60 \mathrm{~m}$ at $300 \mathrm{mb}$ from 1745 through 2345 GMT. Upper level height biases for the physical scheme range from -40 to -60 $m$ at all times while the largest biases for the modified physical scheme approach $-40 \mathrm{~m}$ only at the last time. In the lowest layers, there is a tendency in both of the physical retrieval sets to change from a negative bias to a positive one with time. This seems most definitely related to the decay of the low-level frontal inversion shown in Fig. 8.

The time variability of the precipitable water differences is shown in Fig. 11 for the three retrieval schemes. The physical and modified physical schemes indicate a major moist bias at most times with values approaching $-3.0 \mathrm{~mm}$ at 1445 and 1745 GMT, respectively. This is reduced to a negligible dry bias at 2345 GMT. Although $-3.0 \mathrm{~mm}$ may not seem excessive, it represents approximately $30 \%$ error when the total precipitable water amount of $10.0 \mathrm{~mm}$ is considered. The regression soundings are only slightly biased at the first two times and compare well with the precipitable water determined with the ground truth data from 1745 through 2345 GMT.

\section{c. Vertical structure}

The vertical variation of temperature and moisture biases discussed heretofore indirectly evaluated the

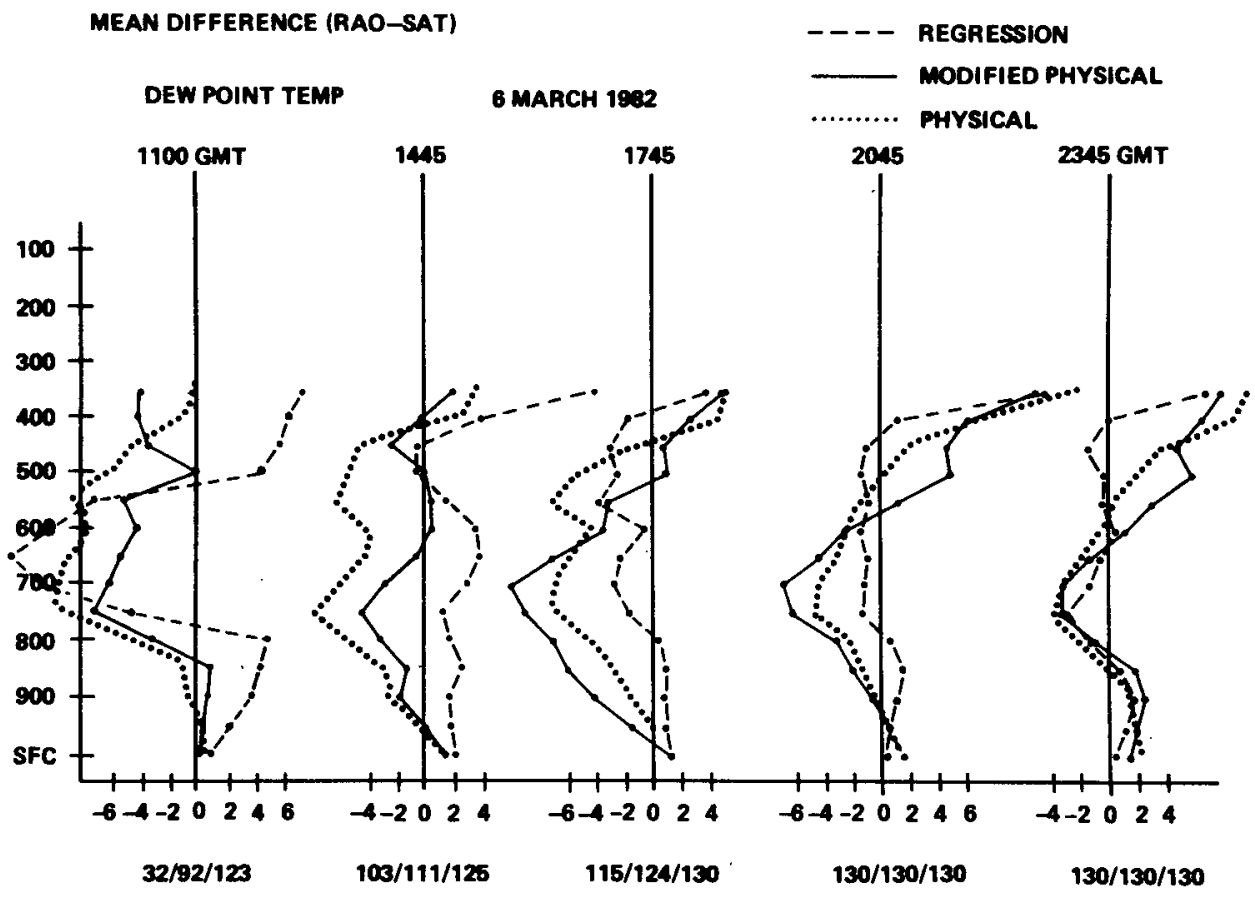

FIG. 9. As in Fig. 7 except for dew-point temperatures. 


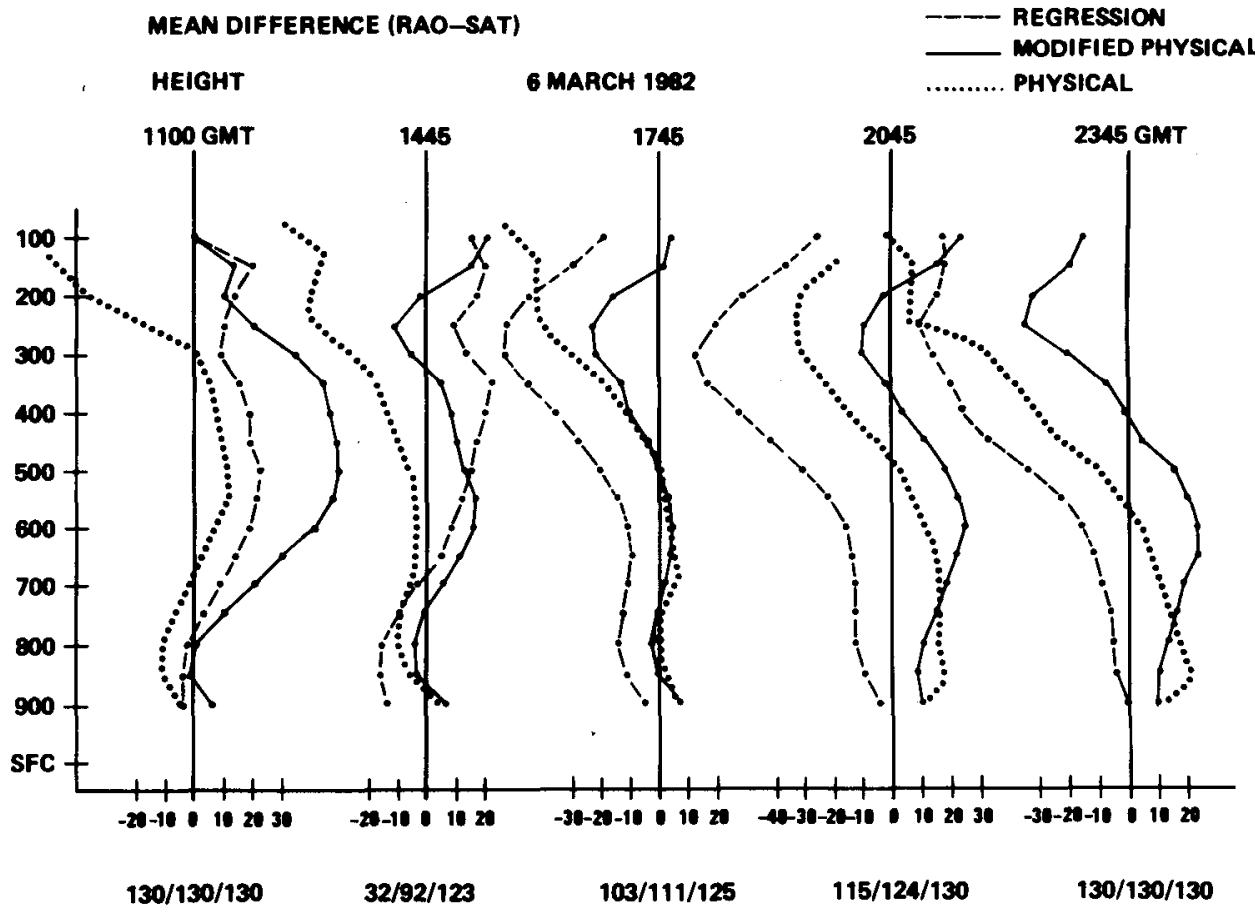

FIG. 10. As in Fig. 7 except for geopotential height values which are in meters.

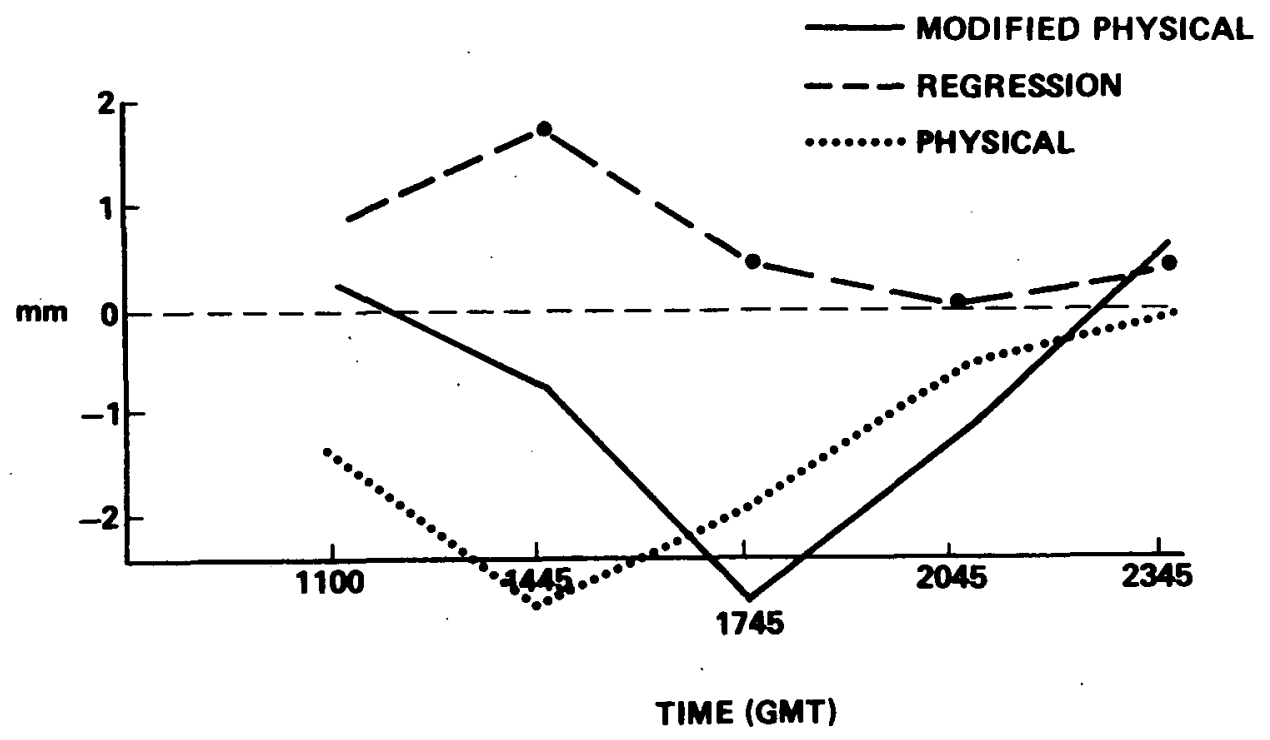

FIG. 11. Mean precipitable water differences between the rawinsonde and satellite grid point values as a function of time. Dashed lines correspond to regression retrievals, solid lines to the modified physical retrievals, and the dotted lines to the physical retrievals. All units are in millimeters. 
vertical resolution of the VAS sounding data sets. To explore this feature in greater detail, Fig. 12 presents grid mean profiles of rawinsonde and satellite data sets at 1745 and 2345 GMT. At 1745 GMT (Fig. 12a-c), mean rawinsonde profiles (solid lines) indicate the presence of a strong frontal inversion extending from about 900 through $750 \mathrm{mb}$. Below $900 \mathrm{mb}$ the boundary layer is gradually being warmed by solar heating.
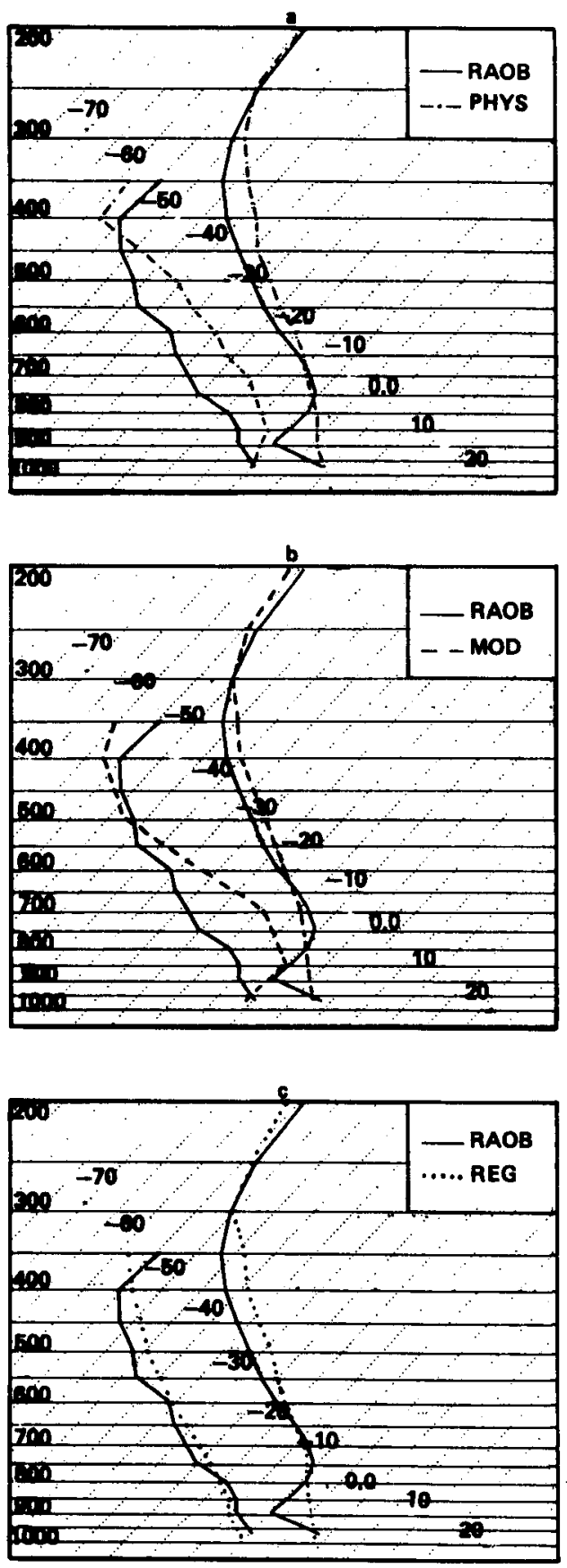

The dew-point profile indicates significant drying above the frontal inversion with depressions greater than $15^{\circ} \mathrm{C}$ up to $350 \mathrm{mb}$ when the profile indicates an increase in moisture. The curve for the physical retrievals (Fig. $12 \mathrm{a}$, dot-dashed line), indicates a very smooth temperature and moisture profile. The frontal inversion is unresolved and the tropopause inversion near $350 \mathrm{mb}$ also is not well captured by the physical retrievals. Thus,
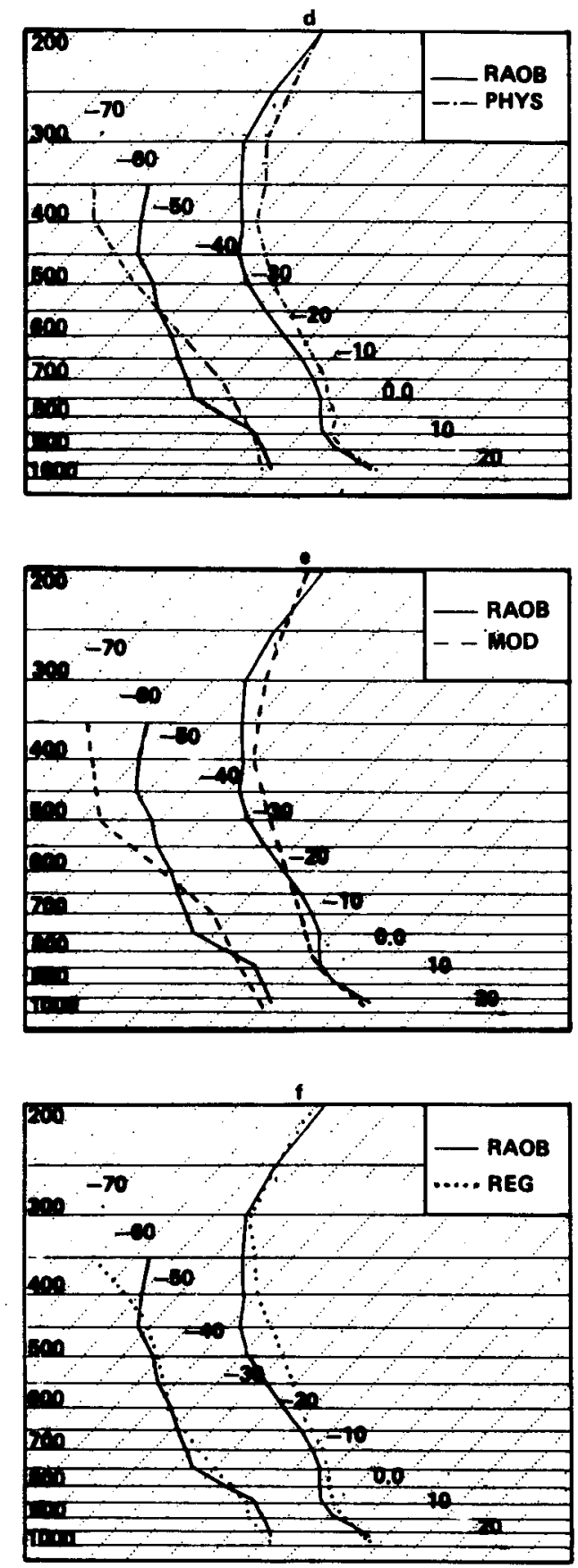

FiG. 12. Grid mean skew-t profiles of temperature and dew point at 1745 GMT for the (a) physical, (b) modified physical, and (c) regression retrievals. Similar profiles at 2345 GMT are presented in d, e, and $\mathrm{f}$ for the three retrieval schemes, respectively. The solid line in each figure corresponds to the rawinsonde grid mean profile shown in Figs. $8 \mathrm{c}$ and $8 \mathrm{e}$. 
it would be difficult to determine the level of the frontal inversion from the satellite profile alone, and the tropopause would be misplaced by at least $100 \mathrm{mb}$. It is important to note that the dew-point depression is almost half that of the rawinsonde between 850 and $400 \mathrm{mb}$.

The mean vertical profile for the modified physical soundings (Fig. 12b, dashed line) also dọes not describe the vertical structure of the atmosphere well. The temperature profile is similar, but the dew-point profile is much too moist. Thus the dew-point profile does not come close to portraying an accurate vertical structure. The mean profile for the regression retrievals (Fig. 12c, dotted line) presents a similar problem with temperature, but shows a substantial improvement over both of the physical retrieval sets in determining the vertical moisture structure. The regression dew-point profile is within several degrees of that of the rawinsonde at all levels and portrays the lapse rate of dew point quite well. It should be noted that the rawinsonde dew point contains no significant change in lapse rate from the surface to $400 \mathrm{mb}$ and therefore should be less difficult to represent.

At 2345 GMT (Fig. 12d-f), the rawinsonde network indicates an ill-defined frontal inversion and a weaker and less well-defined middle and upper troposphere inversion than at 1745 GMT. The moisture profile is beginning to show more of a subsidence inversion with rapid drying above $850 \mathrm{mb}$. The physical retrieval mean temperature profile (Fig. 12d) defines the vertical temperature structure of the atmosphere somewhat better than it did at 1745 GMT. This is undoubtedly due to the lack of strong inversions at this time. How- ever, the physical retrievals keep an almost constant dew-point depression with height and do not adequately capture the dry air aloft. The modified physical retrievals (Fig. 12e) present a different picture. While the temperature profile is different, it does not show major improvement over the physical one, just a different type of bias. There is only a hint of the lowered tropopause inversion at $400 \mathrm{mb}$. The dew-point profile for the modified physical scheme indicates substantial vertical structure but does not closely correspond to the rawinsonde profile. The regression retrievals at 2345 GMT (Fig. 12f) do a fair job of describing the vertical temperature and moisture structure. The major inversion at the tropopause is portrayed well at $300 \mathrm{mb}$; however, the lessening of the temperature lapse rate in the 500 to $400 \mathrm{mb}$ layer is missed. The dew-point profile again does a good job of representing the moisture structure; the almost constant lapse rate of dew-point temperature lacks the drying due to subsidence as indicated in the rawinsonde profile, however.

\section{d. Horizontal structure}

VAS is believed capable of determining mesoscale horizontal structure in the atmosphere because of its small spatial field of view and because only limited horizontal averaging is needed to provide an acceptable signal-to-noise ratio. A measure of the satellite's ability to resolve horizontal structure is provided by gradient information of the various parameters. Table 7 presents time composited means and standard deviations of differences between the satellite and rawinsonde temperature gradients (magnitude) calculated over the me-

TABLE 7. As in Table 2 except for the magnitude of the temperature gradient. Units are in ${ }^{\circ} \mathrm{C} / 100 \mathrm{~km}$.

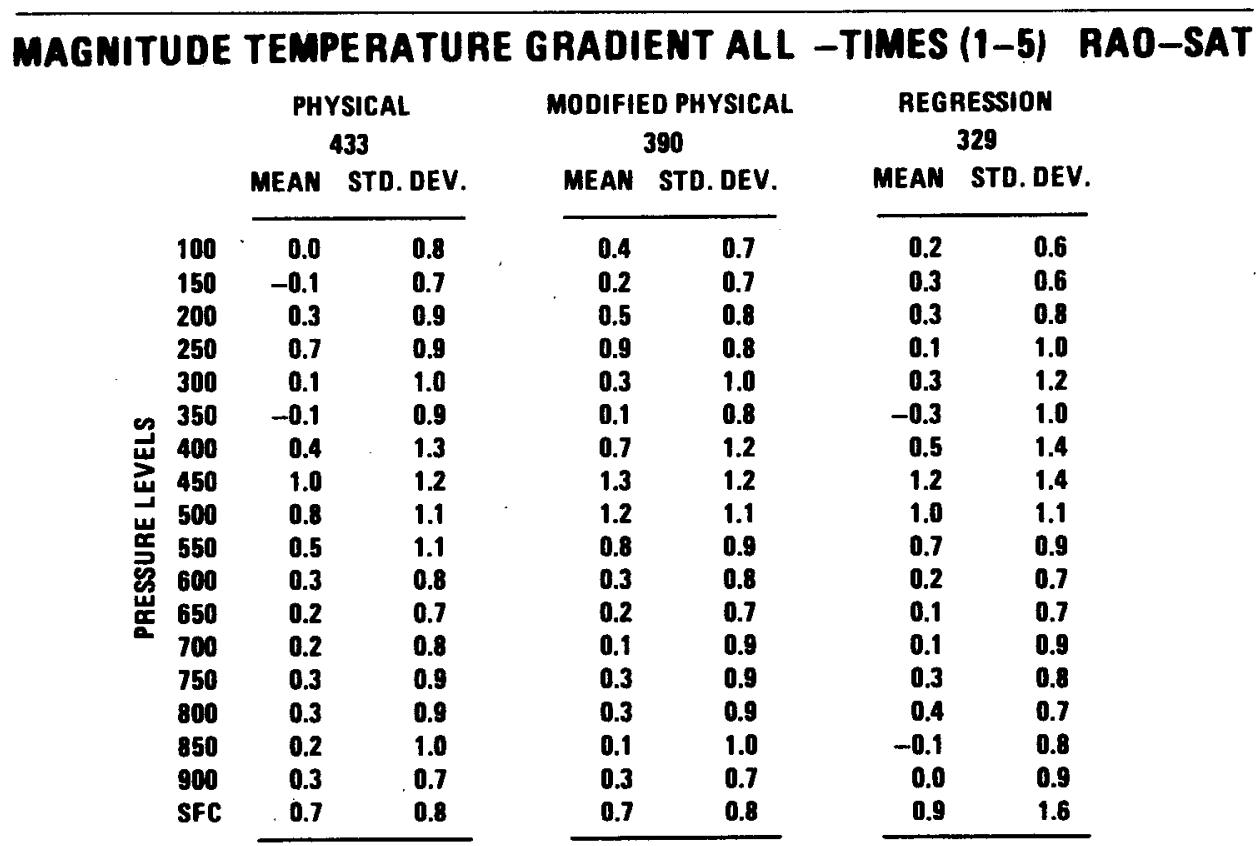


soscale grid region. The number of grid points over which the statistics are calculated is reduced due to the centered finite differencing technique. The satellite temperature gradients are somewhat weaker than those of the rawinsonde (rao - sat $>0$ ). Maximum differences of $1.0-1.3^{\circ} \mathrm{C} / 100 \mathrm{~km}$ appear around $500 \mathrm{mb}$. For typical mesoscale features of $400-600 \mathrm{~km}$ this can be quite significant. Differences in the lower and upper levels are considerably smaller, thereby providing a better estimate of the actual temperature gradient. In the mean, none of the retrieval sets represent temperature gradients better than the others. Negative differences occur at several levels, indicating that the satellite temperature gradient is stronger than that of the rawinsonde. At first this situation is difficult to understand, but several explanations are possible. It is doubtful that over the relatively large mesoscale domain of the analysis region that the gradient is actually much stronger than that of the rawinsonde. This might be true at very small scales (below that resolvable by the rawinsonde) but not over the entire grid region. Vertical and horizontal aliasing by VAS may explain tighter than expected gradients over a given region. Also, stronger gradients may appear where the rawinsonde gradients are relatively small. Standard deviations of the gradient differences indicate largest variations in the $500-300 \mathrm{mb}$ layer where values exceed $1.0^{\circ} \mathrm{C} / 100 \mathrm{~km}$. This trend is almost identical for each VAS data set.

Figure 13 is an example of the horizontal structure derived from VAS for $500 \mathrm{mb}$ temperature at 2345 GMT. The rawinsonde data (Fig. 13a) indicate a cold pocket situated over the north central portion of the mesoscale region. A strong gradient exists around this cold area with a west-east orientation on the west side and a somewhat tighter gradient to the southeast. The physical retrievals (Fig. 13b) provide a rather bland temperature gradient with a north-south orientation. It is considerably weaker than the rawinsonde data and fails to capture the cold pocket over the network. The modified physical retrievals (Fig. 13c) show a similarly weakened gradient but indicate a cold pocket in the northern part of the region. The regression retrievals (Fig. 13d) capture the cold pocket fairly well and center it near the rawinsonde-derived location. The resultant gradient is somewhat stronger than the two physical retrieval sets but is still orientated in the north-south direction. None of the schemes properly capture the reversal of the temperature gradient to the west of the cold region. A warm bias is also apparent in the fields as was pointed out in previous sections.

Table 8 presents time composited results on dewpoint temperature gradients (magnitude) for each retrieval scheme. In general, each scheme indicates reduced dew-point gradients over the mesoscale region with maximum values surpassing $3.0^{\circ} \mathrm{C} / 100 \mathrm{~km}$ at 600 and $650 \mathrm{mb}$. There are a few levels where the satellitederived gradients are stronger than the rawinsonde, and
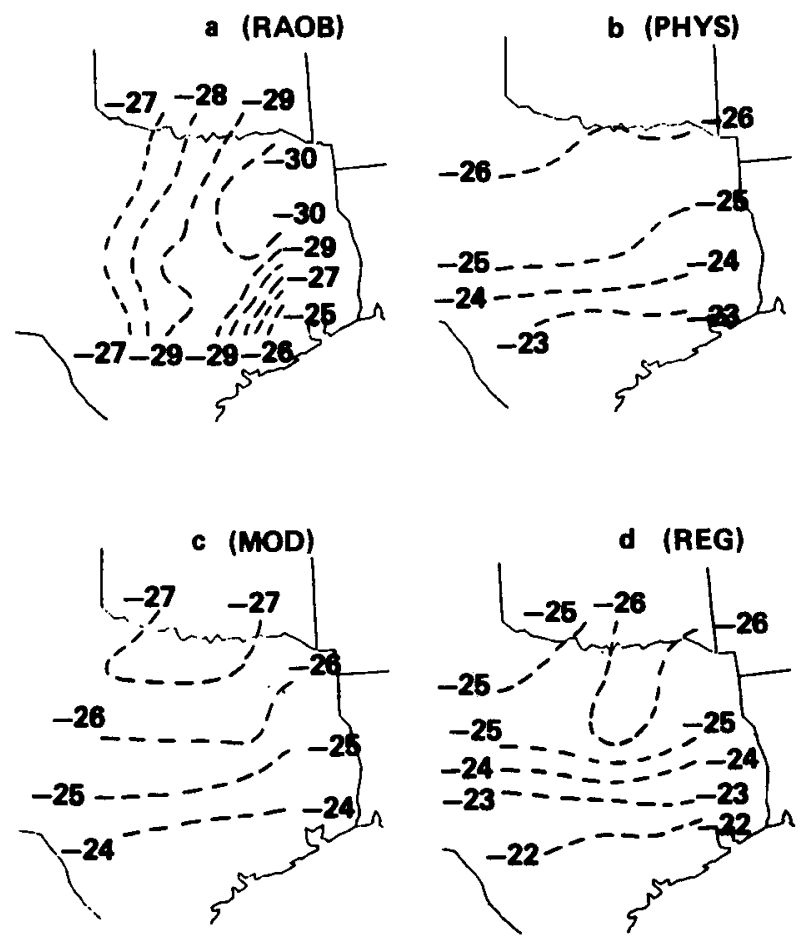

FiG. 13. Horizontal analysis of temperature at $500 \mathrm{mb}$ for 2345 GMT 6 March 1982 for the (a) rawinsonde, (b) physical, (c) modified physical, and (d) regression soundings. All units are in ${ }^{\circ} \mathrm{C}$.

explanations given earlier are also applicable here. Standard deviations range from $1.0^{\circ} \mathrm{C}$ in the lower levels to $3.3-4.0^{\circ} \mathrm{C} / 100 \mathrm{~km}$ at $550 \mathrm{mb}$. Standard deviations for the regression retrievals are somewhat larger than for the two physical data sets indicating more uncertainty in this horizontal measurement. This point is important since the regression retrievals produced the least biased moisture results in the grid mean (Tables 3 and 6). With this further evaluation, it seems that the regression soundings represent the mean moisture distribution quite well but do not provide detailed mesoscale variability.

Figure 14 contains horizontal patterns of dew point at $700 \mathrm{mb}$ for $2345 \mathrm{GMT}$. The rawinsonde data (Fig. 14a) indicate a dry region in the northern portion of the analysis area stretching down to the southeast. Increasing moisture (warmer temperatures) exists with a tighter gradient to the south. None of the VAS retrieval analyses provide a very accurate representation; however, the modified physical retrievals appear to do the best, since the dry region and the increasing dew-point gradient to the south are captured. The only questionable area is the extreme northwestern portion. The physical and regression retrievals do an equally poor job of defining the dew-point structure. Both present a dry region centered over the network, but only weak gradients surround it. Despite their lack of detailed mesoscale agreement, the data do present a smoother 
TABLE 8. As in Table 2 except for the magnitude of the dew-point temperature gradient. Units are in ${ }^{\circ} \mathrm{C} / 100 \mathrm{~km}$.

MAGNITUDE DEWPOINT TEMPERATURE GRADIENT ALL-TIMES (1-5) RAO-SAT

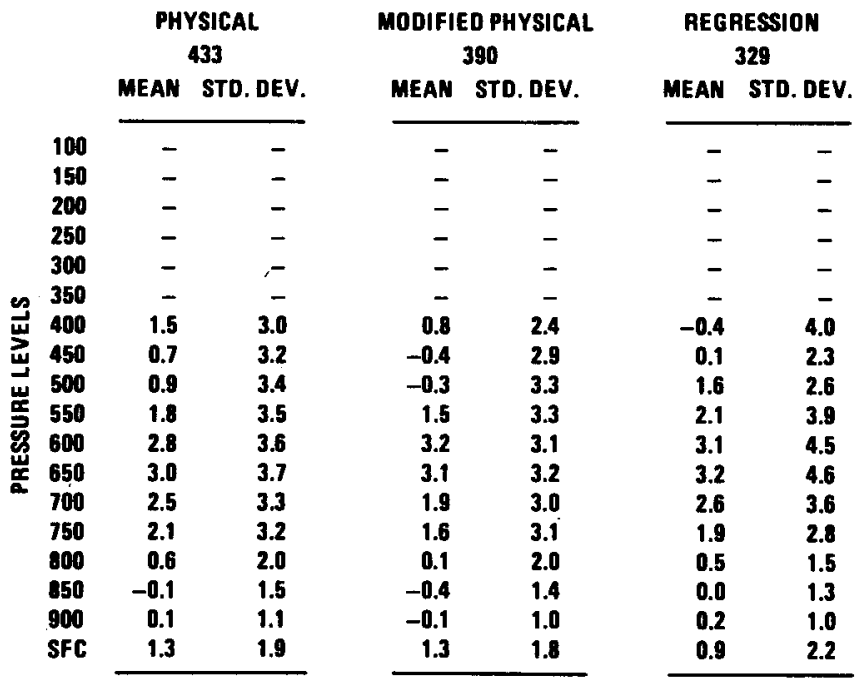

version of the rawinsonde dew-point field that may provide useful information at a somewhat larger scale.

\section{e. First guess information}

The application of remote sensing instruments to the retrieval of temperature and moisture profile in- a (RAOB)

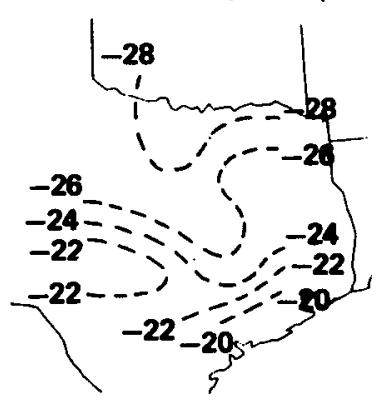

c (MOD)

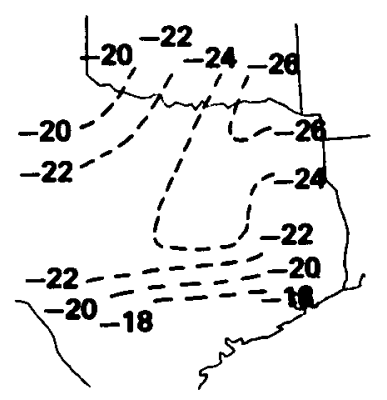

b (PHYS)

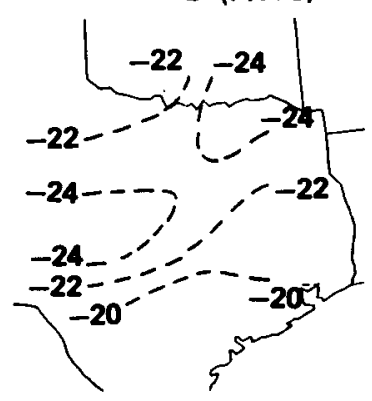

d (REG)

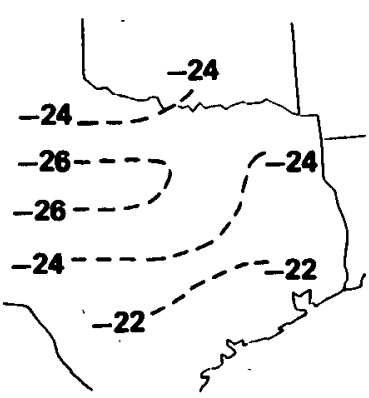

FIG. 14. As in Fig. 13 except for dew-point temperature at $700 \mathrm{mb}$. formation necessitates inverting the radiative transfer equation. The solutions can take many forms, but in each case some a priori information is needed about the atmosphere. This information must consist of an atmospheric model (with thermal and moisture characteristics) from which the transmission of radiation through the atmosphere can be calculated. Physical retrieval schemes like the two evaluated in this paper use an iterative process to improve on a first guess temperature and moisture profile. Any temperature and moisture profile can be used; however, an atmospheric profile which is representative of the actual sounding environment produces the best retrievals. The procedure used to produce the regression soundings also uses first guess temperature and moisture information but in a somewhat different manner. These profiles are used along with colocated radiance measurements to develop relationships between the two data types. These relationships are then applied to other radiance measurements. Chesters et al. (1982) have indicated that sounding results are best when local soundings (those having structural features similar to the sounding environment) are used to develop the regression matrix.

The first guess information used in the two physical retrieval schemes was the initial and 12-h forecast fields from the operational Limited Fine Mesh (LFM) numerical model run at the National Meteorological Center. For the five time periods at which retrievals were made on 6 March 1982, temperature and moisture profiles were derived from the LFM grid point data. At 1100 and 2345 GMT, the initial and $12 \mathrm{~h}$ forecast fields were used, respectively. For the three inbetween times, a linear interpolation to the sounding time was used from the initial and $12 \mathrm{~h}$ forecast.

To evaluate the structural content of the first guess LFM data, they were bilinearly interpolated to the me- 
soscale grid (Fig. 2). The gridded LFM data then were evaluated in a similar fashion to the satellite data, and mean and standard deviations of the differences between the rawinsonde and the LFM first guess data were calculated and are presented in Table 9. For the composite results, the first guess data show some of the same temperature and moisture biases as the physical and modified physical retrievals described earlier. A low-level temperature bias couplet is present below $700 \mathrm{mb}$ having a magnitude which is intermediate to that of the two physical retrieval data sets (Table 2). A small warm bias (rao - LFM $<0$ ) is present at 500 $\mathrm{mb}$. The warm bias in the satellite retrievals was previously shown to be somewhat stronger at this level and extended over a deeper layer. The first guess data indicate a strong cold bias in the uppermost levels with magnitudes exceeding $3^{\circ} \mathrm{C}$ at several levels. This is similar to the modified physical retrievals which show the same trend. The physical retrievals show a tendency towards a cold bias at these levels but remain slightly warm biased. Standard deviations of temperature differences for the first guess data are nearly identical to those of the physical and modified physical retrievals, ranging from about $1-2^{\circ} \mathrm{C}$ with a maximum in the middle and upper levels.

It should be noted that in some instances the LFM biases are smaller than those of the satellite retrievals at the corresponding level (e.g., at $500 \mathrm{mb}$ in Tables 2 and 3 compared with Table 9). While this is unsettling,

TABLE 9. Mean and standard deviation of the temperature and dew-point temperature differences between the rawinsonde and LFM first guess grid point data for a composite of the five time periods on 6 March 1982. All units are in ${ }^{\circ} \mathrm{C}$.

\section{LFM GUESS ALL TIMES (1-5) RAO-LFM}

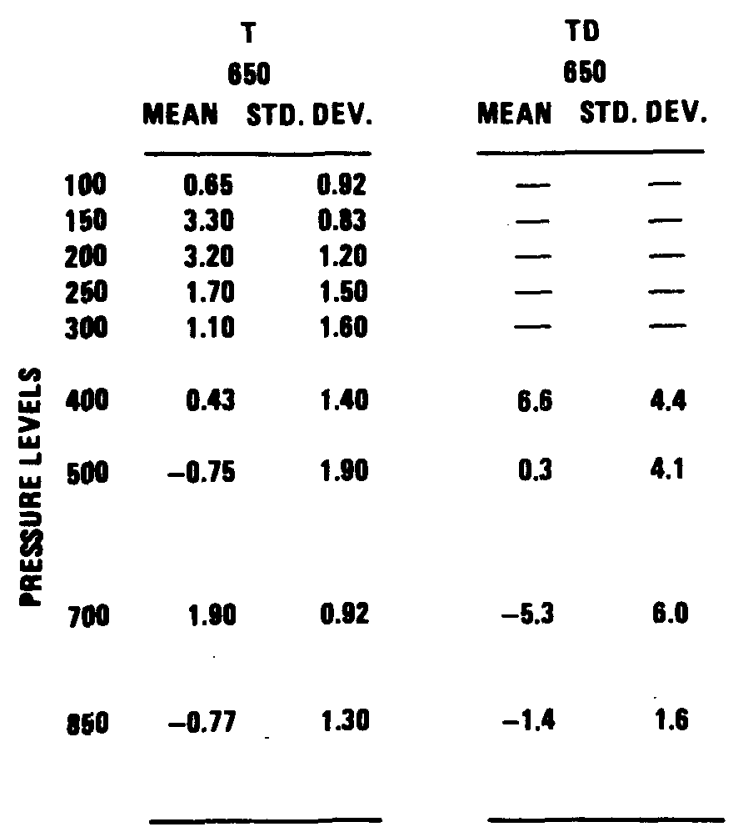

it can be explained by the vertical "aliasing" of temperature and moisture from the broadness of the weighting functions. For dew point in this case, it is fairly obvious that low-level moisture (below $800 \mathrm{mb}$ in Fig. 8) is being detected by VAS channels 7 and 9 (Fig. 1) and in the retrieval process influences the 500 $\mathrm{mb}$ dew-point values. Similar aliasing can occur for temperature and may explain biases which are larger than those of the first guess.

Mean dew-point differences between the rawinsonde and first guess data (Table 9) indicate that the first guess profiles are moist biased in the lower levels and dry biased aloft. This pattern is similar to that of the two physical schemes, however, the dry bias is slightly greater in the LFM data. Standard deviations are also comparable. Such biases are not surprising since some vertical smoothing of the input (rawinsonde) data is performed in the interpolation to the LFM levels during model initialization. It is surprising that (in the all times average) little if any improvement in the vertical structure of the atmosphere is made with VAS.

Figure 15 shows the mean LFM guess profile at 1745 GMT which can be compared to those of the physical retrievals in Fig. 12a, b. Biases in the LFM and satellite sounding data at 1745 GMT are similar to those seen for the composite period (Table 9). The important issue is whether the satellite soundings have improved vertical resolution over the first guess information. With the temperature profiles, the VAS curves are shifted slightly resulting in a different bias pattern. It is not apparent that any significant improvement is made over that of the first guess information at this time period. Above $300 \mathrm{mb}$, there seems to be some improvement over the first guess, mainly in the physical retrievals (Fig. 12a). This improvement, however, seems to be at the expense of a larger bias in the middle layers. A vertical profile of the mean dew-point values from the first guess information at 1745 GMT is also presented in Fig. 15. Figure 12a, b can be used to compare the vertical moisture structure of the satellite data. Dew points from the first guess and the physical retrievals are almost equivalent, while the modified scheme tends to be moister in the lower levels and slightly drier aloft. These results tend to indicate that on the average, minor improvement in the vertical resolution is made with both physical retrieval schemes over that of the first guess information.

The horizontal structure defined by the LFM first guess information should be relatively bland at the mesoscale because of the large-scale information utilized by the model and a relatively course grid spacing. The $500 \mathrm{mb}$ first guess temperature field (Fig. 16) shows only a weak north-south gradient over the region. This figure can be compared to Fig. 13 which presents 500 $\mathrm{mb}$ analyses from the rawinsonde and the VAS retrieval data sets. The first guess temperature field does not represent that of the rawinsonde. There is significantly more variability at the mesoscale. The retrieved VAS soundings from the physical and modified physical 


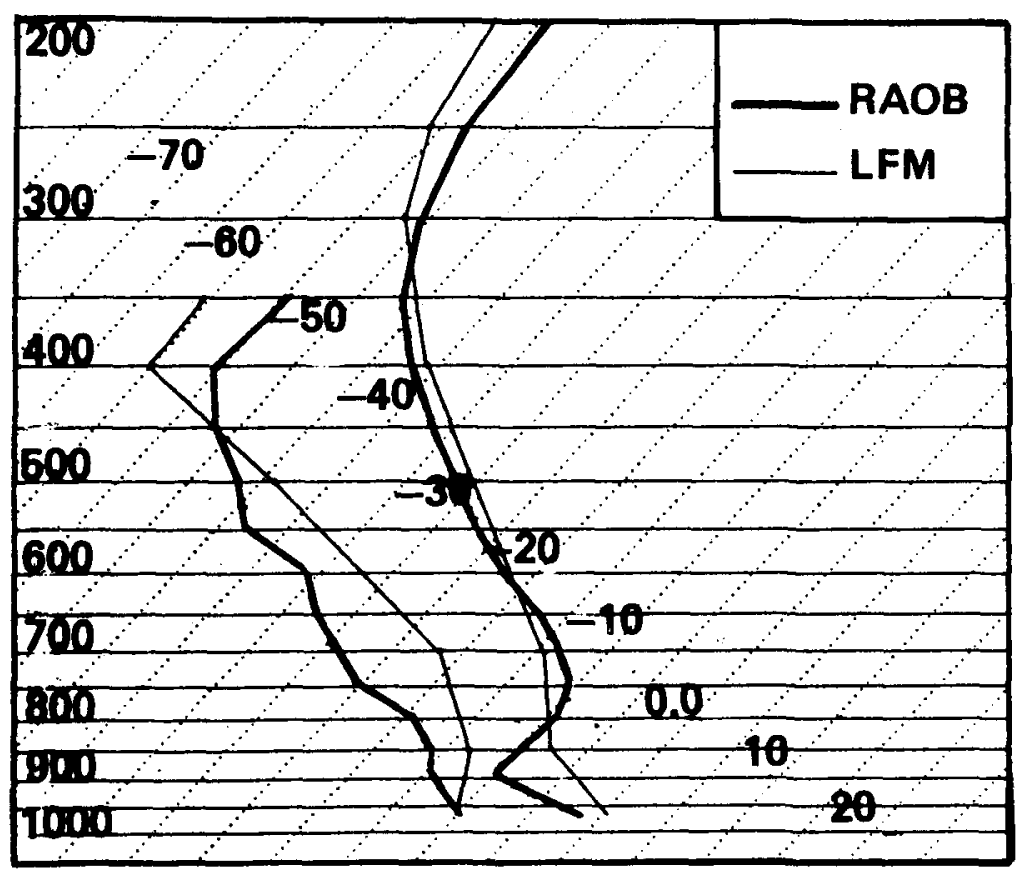

FIG. 15. Grid mean skew- $T$ profile of temperature and dew point from the LFM first guess information at 1745 GMT (thin line). The rawinsonde grid mean profile is presented as the bold line. The VAS profiles for this time are shown in Fig. 12.

schemes improve over the first guess information by increasing the temperature gradient across the network. However, the direction of the gradient in the VAS retrievals remain more like that of the first guess than the rawinsonde. This could be due to a dependence of both physical retrieval schemes on the first guess information (Smith, 1983). The LFM first guess information for dew point at 700 mb on 2345 GMT 6 March

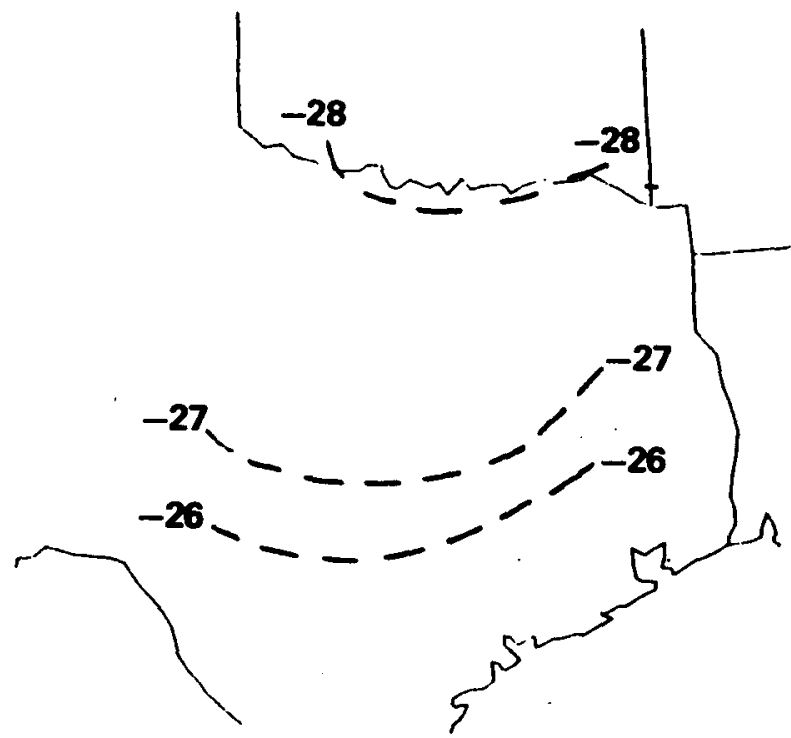

FIG. 16. LFM first guess analysis of $500 \mathrm{mb}$ temperature at 2345 GMT 6 March 1982 interpolated to the mesoscale grid. Units are in ${ }^{\circ} \mathrm{C}$.
(Fig. 17) presents a somewhat different situation. The structure to the LFM dew-point gradient is significant with a fairly strong gradient over the network. This agrees somewhat with the rawinsonde analysis (Fig. 14a), but there is some discrepancy in the northern half of the region. The VAS sounding analysis for dew point at this level and time (Fig. 14b and $14 \mathrm{c}$ ) indicate some similarities to the first guess but also distinctively different structure, some of which correlates well with

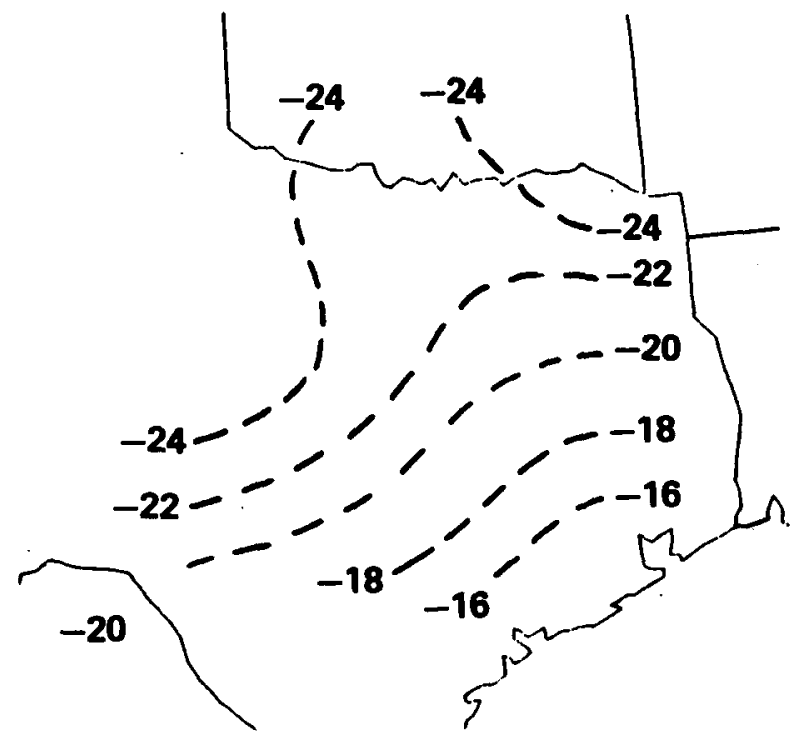

Fig. 17. As in Fig. 16 except for $700 \mathrm{mb}$ dew-point values. 

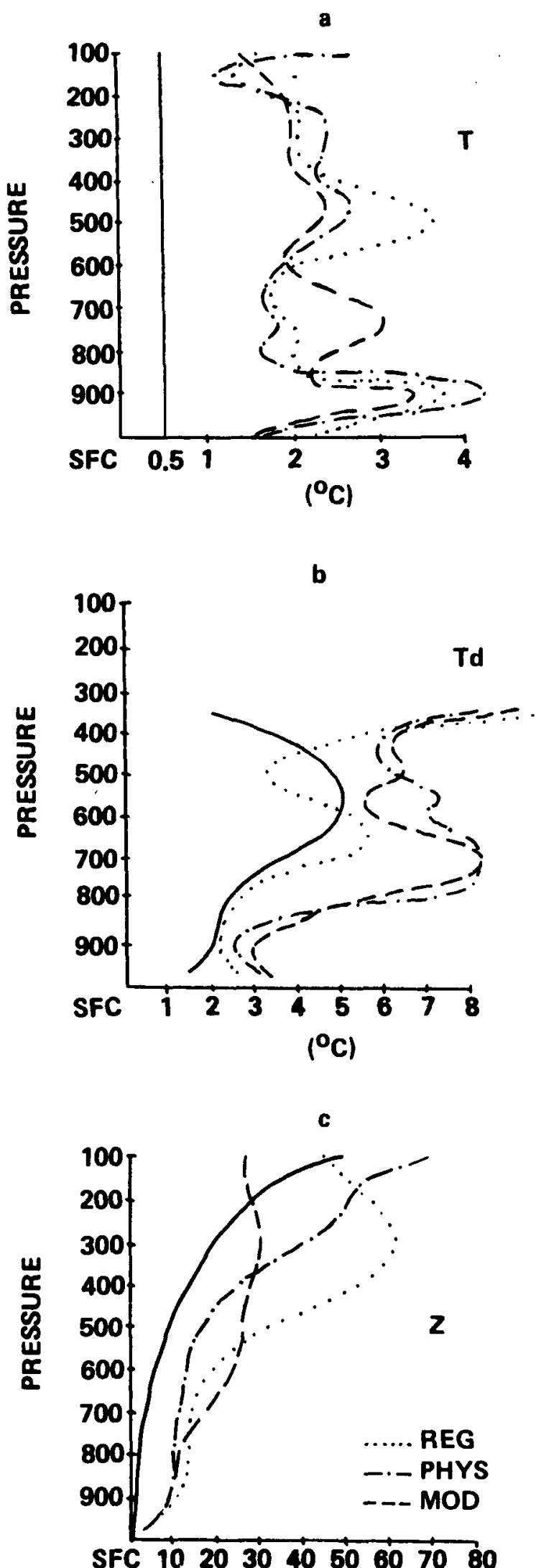

(m) that of the rawinsonde and discussed in the previous section.

It is difficult to evaluate the dependence of the regression retrievals on the first guess information in the same way because that scheme does not use the information in a manner similar to that of the physical schemes. The information used by the regression scheme contains significantly more vertical structure than the LFM first guess profiles ( $25 \mathrm{mb}$ values of temperature and dew point as opposed to seven layers of information from the LFM). However, this vertical structure is lost or hidden by the coarse vertical resolution of the VAS channels (Fig. 1). The retrieval algorithms may not be able to retrieve this structure and thereby produce soundings of the quality presented in this paper. It would seem that improved vertical resolution in satellite sounding data, above what has been presented here, lies with an instrument having more channels which better delineate the vertical structure atmosphere.

\section{Data discrepancies and error bounds}

The findings presented above were based on the assumption that the rawinsonde data accurately portray the "real" mesoscale structure of the atmosphere. For the most part, this assumption is valid since radiosonde data are conventional measurements with proven reliability. The special experiment data set was the subject of rigorous data checks during the reduction process (Sienkiewicz, 1982). Nonetheless, instrument error is a factor which has not been considered thus far and may provide some further explanation for the rawinsonde-satellite discrepancies. Figure 18 presents rms errors expected of the rawinsonde data as a function of pressure (Fuelberg 1974). These values are based solely on instrument constraints. Also presented are the rms errors for the three retrieval sets presented above based on the composite rms difference between the rawinsonde and VAS sounding data. The rms temperature error for the rawinsondes is $0.5^{\circ} \mathrm{C}$ at all levels (Fig. 18a). This is substantially smaller than that of each retrieval scheme where values range from $2-3^{\circ} \mathrm{C}$ at most levels. Figure $18 \mathrm{~b}$ presents the same comparison for dew-point temperature. In this case, a rawinsonde rms relative humidity error of $10 \%$ translates into a varying dew-point error for the rawinsonde. In the cold, dry, middle troposphere, the rms errors become greater than $4^{\circ} \mathrm{C}$; however, rms errors for the physical and modified physical retrievals still exceed this value by several degrees. The rms errors for the

FIG. 18. Root-mean-square (rms) errors for rawinsonde data as a function of pressure (Fuelberg, 1974) and rms differences between grid point values of rawinsonde and satellite data for the composite results for (a) temperature, (b) dewpoint, and (c) geopotential height for each satellite retrieval scheme. Dotted lines indicate the regression results, dot-dashed the physical retrieval results, and dashed the modified physical retrieval results. Units are in ${ }^{\circ} \mathrm{C}$ for the temperature and dew-point curves, and in meters for the height curves. 
regression data are similar to those of the rawinsonde except above $450 \mathrm{mb}$ where they greatly exceed the rawinsonde's error values. This is consistent with the comparisons in the previous section which indicate that the dew points from the regression retrievals are quite good in the mean but suffer slightly in horizontal detail. The rms errors for geopotential height calculated with assumed rawinsonde temperature errors (Fig. 18c) become increasingly larger as the temperature errors accumulate. These errors are still relatively small however, reaching 10,20 , and $50 \mathrm{~m}$ at $500,300,100 \mathrm{mb}$, respectively. The VAS rms errors are considerably larger than those of the rawinsonde at all levels except the uppermost ones. Maximum differences occur in the middle and upper levels. These results suggest that for temperature the rawinsonde errors for the most part contribute little to the observed discrepancies of the rawinsonde-satellite comparisons. However, for dewpoint temperature, the rawinsonde errors may be nearly as large as the rawinsonde-satellite discrepancies, especially in the middle troposphere. Results for geopotential height indicate that below $300 \mathrm{mb}$, rawinsonde height errors are small compared to those of the satellite. Above this level, rawinsonde height errors may account for some of the differences between the two data types.

Another contributing factor to the rawinsonde-satellite discrepancies is the accuracy of the radiometer making the remote measurements. For VAS, biases and errors in the radiance measurements can be quite large (Menzel et al., 1981); however, the biases can be corrected, and with multiple spins and spatial averaging, the error is reduced to less than $0.5 \mathrm{~K}$ in each channel. The effects of this error further limit the vertical resolving capabilities of the instrument and degrades the resolution in the retrieved profiles. In addition, clouds can contaminate what may seem to be clear fields of view and therefore bias a particular radiance measurement. Although manual and automated techniques are used in the retrieval process to eliminate cloudy radiance measurements (Smith, 1983; Lee et al., 1983), small-scale cloud features (less than $15 \mathrm{~km}$ in diameter) can often go undetected.

One of the major factors affecting rawinsonde-satellite comparisons is the difference in the type of measurement obtained with each instrument. Rawinsonde values are virtually point measurements of quantities which vary greatly in space. This is especially true for rawinsonde moisture measurements which often exhibit significant moisture variations over thin layers of the atmosphere and at small horizontal distances. On the other hand, the satellite's temperature and moisture profiles are derived from radiance measurements which originate from thick layers of the atmosphere and over relatively large horizontal extents. Thus, each satellite radiance measurement (single field of view) is actually a volumetric average from a slab of the atmosphere. This factor has been addressed by Bruce et al. (1977) who found that the sampling differences can often ac- count for several degrees of discrepancy between the rawinsonde and satellite measurements. The VAS retrievals evaluated in this paper are good in comparison to what one might expect given these confines and constraints.

\section{Summary and conclusions}

This paper has presented an evaluation of VAS sounding data from three different retrieval algorithms in order to determine the accuracy and representativeness of the satellite sounding products for one case study. The verifying data consisted of special rawinsonde observations having similar spatial resolution to that available from VAS. Special procedures were performed to produce rawinsonde and satellite profiles data valid at the same times at all pressure levels, grid point values over the same mesoscale domain, and analyses which allowed for the same potential for detail in each data field.

Mean and standard deviations of differences between the rawinsonde and satellite grid point values were very useful in determining biases and errors in the data. On the average, large temperature and moisture biases existed for all three retrieval sets at those levels where inversions were prominent. Differences did exist between the various retrieval sets, particularly when time variability was considered. It is difficult to say which of the three retrieval schemes is best since none consistently describe the mesoscale environment better than the others. The two physical schemes tended to produce soundings which were too moist while the regression moisture retrievals were almost unbiased. As a measure of error in the VAS retrievals, standard deviations of the difference between the satellite values and the ground truth were evaluated. In most cases the standard deviations were largest in the upper levels. Values ranged from 1 to $2^{\circ} \mathrm{C}$ for temperature and 3 to $5^{\circ} \mathrm{C}$ for dew point for each retrieval scheme.

Derived parameters from the VAS soundings reflected the biases in the original temperature and moisture profiles to a large extent. Geopotential height profiles were generally good, especially for the modified physical retrievals. For the regression and physical retrievals, heights became too large in the upper levels. Standard deviations for heights range from 20 to $30 \mathrm{~m}$ above $600 \mathrm{mb}$ but were somewhat smaller below.

Horizontal gradients defined by the VAS data were generally weaker than those of the rawinsondes. Temperature gradient differences of $1^{\circ} \mathrm{C} / 100 \mathrm{~km}$ were not uncommon at various levels. In some cases the mesoscale gradients were not properly orientated with that of the rawinsonde.

An evaluation of the first guess information indicated that very little improvement was made in the vertical structure over that of the first guess information. However, significant improvement was made in the horizontal structure over that provided by the first guess data. There seemed to be some dependence of the two 
physical retrieval sets on this information, and this may explain the disorientation of the gradients, particularly in the middle and upper levels.

The errors and discrepancies highlighted in this paper can be attributed to a number of phenomena. First, the rawinsonde data are not error free, and this may account for some of the differences, especially in the dew-point comparisons. However, the major cause for disagreement is probably due to sampling differences between the two types of measurements. The satellite radiance measurements represent a volumetric average of the temperature and moisture distribution, whereas the rawinsonde is virtually a point measurement. This tends to reduce the vertical resolution of the instrument and limits the amount of vertical information recoverable by any retrieval method. The spatial and temporal averaging of individual fields of view reduces the horizontal information content and thereby produces a smoother representation of the mesoscale environment.

The VAS soundings from these and other retrieval schemes must be used with caution. While the expected error (standard deviation) in the retrievals evaluated here is relatively constant, biases which affect the direct use of satellite soundings vary with level, time, and with retrieval scheme. Certainly, the use of satellite soundings with other conventional measurements for diagnostic analysis or in numerical models without accounting for the bias is unwise. If the satellite biases are presumed to be mainly retrieval-dependent and uncorrelated with the structure of the atmosphere, then the bias patterns presented in this paper could be used to "correct" the satellite soundings and their use would not be restricted. However, this is not the general rule and therefore limits the applications of satellite soundings.

The most logical approach in the use of VAS soundings in diagnostic and numerical studies may be to focus on the spatial and temporal information provided by the high resolution data. The use of time tendencies and gradient information is not precluded by absolute difference errors between VAS and rawinsonde information. The gradient results presented in this paper support their use to infer subsynoptic scale structure in this fashion. Furthermore, the advancement of objective analysis schemes and assimilation techniques already allow for the use of satellite gradient information.

Acknowledgments. A number of individuals have contributed to this research and the final version of the paper presented here. Drs. Bill Smith of CIMSS and Kit Hayden of NESDIS provided the two physical re- trieval data sets and many valuable comments. Drs. Louis Uccellini and Dennis Chesters of NASA's Goddard Space Flight Center supplied the regression retrievals used in this evaluation as part of the VAS Demonstration. This work was supported under the Universities Space Research Association's (USRA) Visiting Scientist Program at Marshall Space Flight Center through NASA Contract NAS8-34767. NASA's support of this research and the USRA program is fully appreciated.

\section{REFERENCES}

Anthony, R. W., and G. S. Wade, 1983: VAS operational assessment findings for Spring 1982/83. Thirteenth Conf. on Severe Local Storms, Boston, Amer. Meteor. Soc., J23-J28.

Bruce, R. F., L. D. Duncan and J. H. Pierluissi, 1977: Experimental study of the relationship between rawinsonde temperatures and satellite derived temperatures. Mon. Wea. Rev., 105, 493-496.

Chesters, D., L. W. Uccellini and A. Mostek, 1982: VISSR Atmospheric Sounder (VAS) simulation experiment for a severe storm environment. Mon. Wea. Rev., 110, 198-216.

- - - and W. D. Robinson, 1983: Low-level water vapor fields from the VISSR Atmospheric Sounder (VAS) "Split Window" channels. J. Clim. Appl. Meteor., 22, 725-743.

Fuelberg, H. E., 1974: Reduction and error analysis of the AVE II pilot experiment data. NASA CR-120496, Marshall Space Flight Center, 140 pp. [Avail. NTIS N75-12531]

- , and G. J. Jedlovec, 1982: A sub-synoptic-scale kinetic energy analysis of the Red River Valley tornado outbreak (AVESESAME I). Mon. Wea. Rev., 110, 2005-2024.

Hill, C. K., and R. E. Turner, 1983: NASA's AVE/VAS program. Bull. Amer. Meteor. Soc., 64, 796-797.

Lee, T-H., D. Chesters and A. Mostek, 1983: The impact of conventional surface data upon VAS regression retrievals in the lower troposphere. J. Climate Appl. Meteor., 22, 1853-1874.

Menzel, W. P., W. L. Smith and L. D. Herman, 1981: VAS radiometric calibration: An inflight evaluation from intercomparisons with HIRS and radiosonde measurements. Appl. Opt., 20, 36413644.

Petersen, R. A., L. W. Uccellini, A. Mostek and D. Keyser, 1984: Delineating mid- and low-level water vapor patterns in preconvective environments using VAS moisture channels. Mon. Wea. Rev., 112, 2178-2198.

Sienkiewicz, M. E., 1982: AVE/VAS II: 25 mb Sounding Data. NASA CR-170691, Marshall Space Flight Center, 303 pgs. [Avail. NTIS N83-17013]

Smith, W. L., 1968: An improved method for calculating tropospheric temperature and moisture from satellite radiation measurements. Mon. Wea. Rev., 96, 387-396.

- 1970: Iterative solution to the radiative transfer equation for the temperature and absorbing gas profile of an atmosphere. Appl. Opt., 9, 1993-1999.

- , 1983: The retrieval of atmospheric profiles from VAS geostationary radiance observations. J. Atmos. Sci., 40, 2025-2035.

- , and F. X. Zhou, 1982: Rapid extraction of layer relative humidity, geopotential thickness, and atmospheric stability from satellite sounding radiometer data. Appl. Opt., 21, 924-928.

, V. E. Soumi, W. P. Menzel, H. M. Woolf, L. A. Sromovsky, H. E. Revercomb, C. M. Hayden, D. N. Erickson and F. R. Mosher, 1981: First sounding results from VAS-D. Bull. Amer. Meteor. Soc., 62, 232-236. 